\title{
Telephone Support in an Internet-Based Treatment for Sleep Problems in Early Childhood
}

\author{
Angelika A Schlarb ${ }^{1 *}$, Isabel Brandhorst ${ }^{2}$, Elisabeth Peters ${ }^{2}$ and Martin Hautzinger ${ }^{2}$ \\ ${ }^{1}$ Department of Psychology, University of Tuebingen, Tuebingen, Germany \\ ${ }^{2}$ University of Bielefeld, Bielefeld, Germany
}

\begin{abstract}
Study background: Mild to severe sleep problems are reported in $3 \%$ to $56 \%$ of young children. Behaviourbased treatments are highly effective in improving children's sleep. The purpose of this work was to examine the efficacy of an Internet-based intervention for young children's sleep disturbances (Mini-KiSS Online) and to assess the effect of telephone support for parents.
\end{abstract}

Methods: Two intervention conditions (written information with or without additional weekly telephone support) were compared to a waiting-list control condition. $\mathrm{N}=199$ parents with their children (aged 6-63 months) were randomly assigned to one of the study conditions. The treatment consisted of six written information modules based on a cognitive-behavioural approach. One of the treatment groups had additional weekly telephone support. Data of sleep diary, parental behaviour, CBCL 1.5-5 (pre, post, 3-month follow-up) and treatment evaluation were collected.

Results: Acceptance of Mini-KiSS Online was high. Children in both treatment conditions showed significant increase in sleep efficacy and reductions in sleep onset latency, duration of night waking, or subjective global ratings while there was no or less change in the control condition. Parents of both treatment conditions reduced their parental presence and physical contact to the child. A benefit of personal assistance was found for treatment evaluation and dropout rates.

Conclusion: Mini-KiSS Online is an effective and highly accepted internet-based intervention to reduce sleep problems in young children. Personal telephone assistance counted for higher satisfaction and lower dropouts but not for further improvement of the sleep behaviour of the child.

Keywords: Sleep problems; Infant; Internet-based intervention

\section{Introduction}

Up to $60 \%$ of parents of infants or toddlers complain about their child having a sleep problem when directly asked [1]. Studies using more objective diagnostic criteria still show prevalence rates of $3 \%$ to $56 \%$ for mild to severe behavioural sleep disturbances [1-9]. For some sleep problems in young children it seems rather to be a developmental difficulty than a persistent disorder [4]. But longitudinal data indicate that a meaningful number of disturbances ( $14.6 \%$ to $41 \%)$ persist over a longer period and thus need to be considered [4,7-10]. As research has shown, sleep problems are associated with severe impairments in infants and toddler. There is evidence for an association between persistent sleep problems and reduced concentration [9], later diagnosis of attention deficit hyperactivity disorder [11], increased injury risk [12-14], increased somatic complains [15], increased risk of being over-weight or obese in later childhood [16,17], presumed impaired cognitive and psychomotor development [18], and more negative affectivity or temper tantrums $[9,15]$.

It has been shown repeatedly, that parental behaviour has some influence on the development and maintenance of infant and toddler sleep disturbances: Routine parental presences at sleep onset or parental soothing behaviour like nursing or rocking coincide with sleep disturbances of the child $[8,15,19-21]$ while offering a sleep aid seems to prevent sleep problems [22]. Putting the child to bed already asleep is strongly associated with frequent night waking [8,23-25], is identified as a predictive factor for chronicity of night waking [26], and is associated with shorter periods of total sleep [22]. Intensive parental engagement during night waking (e.g. little waiting till engagement) also correlates with sleep problems [1,27] while longer parental response times to infant awakenings and leaving the child in the crib at three months were strong predictors for self-soothing at 12 months [28]. Longterm studies [28] and preventive approaches $[29,30]$ indicate that such parental performances are more a cause than a reaction to problematic sleep. Furthermore, treatments teaching parents to reduce their bedtime engagement in order to enhance the child in self-soothing competence are very successful in reducing sleep disturbances [31-35]. Unfortunately, intervention studies usually address parental behaviour but solely measure children's sleep and do not raise parental behaviour by itself.

Barriers are associated with traditional face-to-face interventions, such as time (waiting-, traveling-, therapist-time) and expense of treatment [36,37]. Therefore, studies have explored other more economical modes of delivery, such as interventions based on written information (self-help approaches) with either more or less additional support [36]. Still, it is not clear if parents benefit from additional support or if written information is enough. On the one hand, some studies indicated that parents getting written information perform as

*Corresponding author: Angelika Schlarb, Faculty of Psychology and Sports Science, Department of Psychology, University of Tuebingen, Tuebingen Germany, Tel: ++49(0)521-106-4320, ++49(0)521-106-4320; E-mail: angelika. schlarb@uni-bielefeld.de.

Received: Septmeber 29, 2017; Accepted: November 28, 2017; Published December 08, 2017

Citation: Schlarb AA, Brandhorst I, Peters E, Hautzinger M (2018) Telephone Support in an Internet-Based Treatment for Sleep Problems in Early Childhood. J Psychiatry 21: 435. doi:10.4172/2378-5756.1000435

Copyright: @ 2018 Schlarb AA, et al. This is an open-access article distributed under the terms of the Creative Commons Attribution License, which permits unrestricted use, distribution, and reproduction in any medium, provided the original author and source are credited 
well as parents getting additional personal advice [38-40]. Furthermore, two meta-analyses with several self-help approaches reasoned that therapist-supported treatments produce the same effect sizes as bibliotherapeutic approaches [41,42]. Additionally, interventions addressing other mental health problems in adults did not find differences in performance of participants getting written information and e-mail support compared to performance of participants receiving additionally weekly individual telephone calls [43]. On the other hand, some studies indicate that parents [44,45] or adults [46] benefit from additional guidance in treating sleep problems. Furthermore, Spek et al. [47] concluded in their review of self-help programs for several adult problems that therapist support results in larger effect sizes compared to interventions without therapist support. However, probably because of their high anonymity and reduced structure, exclusive self-help intervention programs tend to produce high numbers of dropouts (partly 50\%) [48] while personal support can reduce dropouts [36].

Aside from the optimal presentation of self-help approaches, it is obvious that the Internet has become a popular source for medical information [49]. Studies indicate that $84 \%$ of parents of infants and toddlers have regular Internet access, $70 \%$ already used the Internet to research pregnancy topics, $40 \%$ searched for information on how to parent a new born, and $27 \%$ searched for information on infant sleep [37]. If asked for their interest in an Internet program to help establish healthy sleep patterns and to prevent paediatric sleep problems, $82 \%$ are at least somewhat interested (22\% extremely interested) [37].

Research groups already indicated the efficacy of Internet-based cognitive-behavioural treatment for insomnia in adults [50-53]. Other internet intervention programmes for different psychological disorders demonstrated their efficacy in several reviews and metaanalyses [36,54-57]. However, online offers to prevent or improve sleep disturbances in young children are still rare [31] even though a survey illustrated that $95 \%$ of health-care providers for young children would recommend such an Internet program [37]. To our knowledge, Mindell et al. [58] were the first to establish an Internet-based intervention for parents of infants and toddlers with mild sleep disturbances in the United States. Based on a sleep questionnaire, parents were provided with suitable written information. Compared with a control group, significant improvements in different sleep variables and maternal selfconfidence were observed [58]. These effects were found to be stable at a one year follow-up [59].

The first online training program for young children in German language known to us was developed and evaluated by our research group [60]. Within six weekly self-learning sessions, based on CBT-I and imaginative techniques, parents were trained to change their behaviour in sleep related situations. Compared to baseline data, significant improvements in children's bedtime behaviour as well as sleep continuity were found at the end of the training. Furthermore, parents showed less dysfunctional strategies at bedtime and night time, like soothing their child to sleep, and felt more confident in difficult sleep related situations. However, a high dropout rate of $46 \%$ after pre-measurement was observed and many parents asked for personal advice.

As the pilot study only compared pre-post-data of the intervention conditions without any control and due to the high dropout rate the present study was initiated. Three conditions were compared: 1) Written information only; 2) Written information plus additional telephone support; 3) Waiting-list control condition.

We assumed that 1) parents would accept the Mini-KiSS Online training; 2) improvements in sleep behaviour of the child happen in the treatment conditions without change in the control condition, 3) parents reduce their soothing behaviour in the treatment conditions without change in the control condition, and 4) that these results are stable over a 3-month follow-up. Furthermore, we expected to 5) increase treatment evaluation and reduce dropouts with personal telephone assistance.

\section{Methods}

\section{Design and procedure}

Families with young children (six months to four years) with sleep problems were recruited via magazines, newspapers and Internet presentation. All further information about the study, its conditions etc. were standardized. E-Mail communication during treatment was also standardized as far as possible. For each family only data of one child were included. After registration families were randomized to one of the three conditions: 1) Written information only (T-); 2) Written information plus additional telephone support $(\mathrm{T}+)$; 3) Waitinglist control condition (C). After getting information about their randomized assignment, all participants were requested to subscribe informed consent. Thereafter, parents filled in a digital sleep diary for the child and online questionnaires in a time frame of approximately 14 days. Subsequently, families of T- and T+ started a six-week MiniKiSS Online treatment with or without personal telephone assistance. Meanwhile, participants of condition C started their six-week waiting time. After treatment or waiting time all parents completed postmeasurement. In addition parents of condition $\mathrm{T}+$ and $\mathrm{T}$ - filled in the 3-month follow-up. After post-measurement, families of condition $\mathrm{C}$ were randomly assigned to intervention with or without personal assistance without further measurements. All procedures conform to the principals outlined by the Declaration of Helsinki.

\section{Participants and dropout}

For number of interested participants, registration, randomization, exclusion and dropout (Figure 1). Initially, 559 families asked for information. Of these, $50 \%(\mathrm{~N}=283)$ were registered and randomized to treatment condition without personal assistance $(\mathrm{N}=91)$, treatment condition with personal assistance $(\mathrm{N}=90)$ or control condition $(\mathrm{N}=102)$. After randomization and having information about their assignment, $23 \%$ of families did not sign informed consent or complete pre-measurement. Thereby, the highest loss was recorded in treatment condition T- without personal assistance (33\%), followed by control condition $\mathrm{C}(24.5 \%)$ and treatment condition $\mathrm{T}+$ with personal assistance (12\%). Of the remaining 218 patients who completed pre-measurement, 19 were excluded because they met exclusion criteria. Families were excluded if the child had a psychiatric disorder or respiratory disease, got sleep influencing medication during measurement, if parents used simultaneous treatment, or if parents exceeded measurement timelines. After pre-measurement and start of treatment or waiting time, self-determined dropout by parents was quite low (overall 10.1\%, T+6.9\%, T- 17.2\%, C 7.2\%). Furthermore, from post-measurement to follow-up an overall dropout of $9.6 \%(\mathrm{~T}+$ $8.6 \%$, T- $10.4 \%$ ) was recorded. As already mentioned, condition $\mathrm{C}$ was not surveyed again after treatment.

Of the 199 children whose parents filled in pre-measurement, 96 were girls $(\mathrm{T}+\mathrm{N}=34, \mathrm{~T}-\mathrm{N}=27, \mathrm{C}: \mathrm{N}=35)$ and 103 boys $(\mathrm{T}+\mathrm{N}=38$, $\mathrm{T}-\mathrm{:}$ $\mathrm{N}=31, \mathrm{C}: \mathrm{N}=34$ ). Overall, they had a mean age of 19.71 months, but more young than older children participated (Figures 2 and 3 ). Two children lived with their single mothers (both condition $\mathrm{C}$ ), one child 


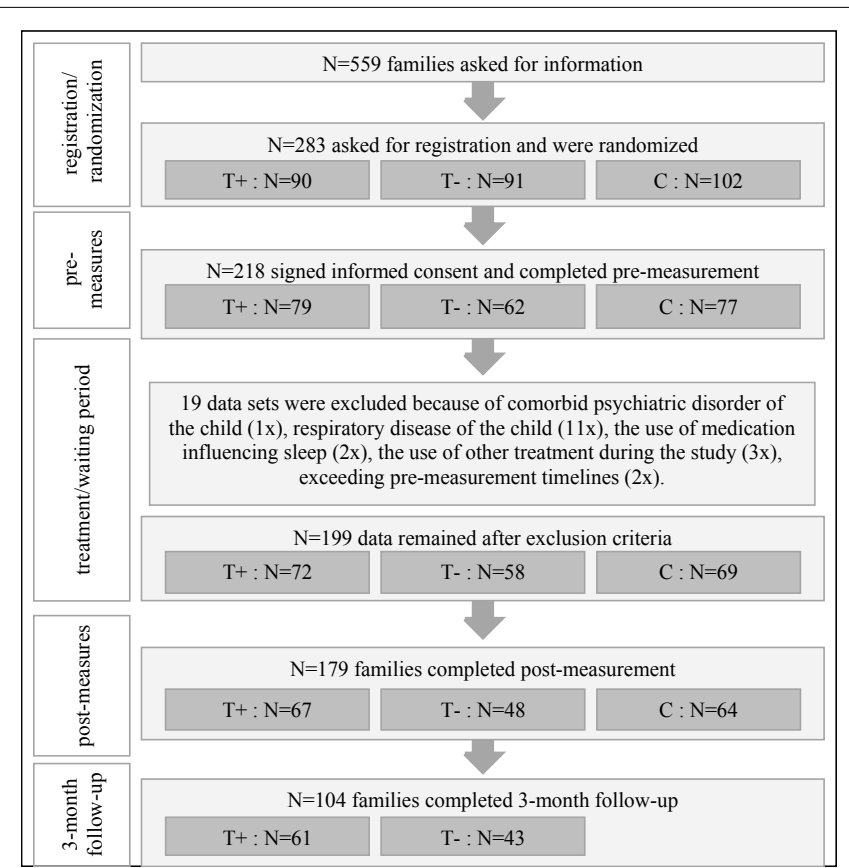

Note: T+: Treatment with personal assistance; T-: Treatment without personal assistance; C: Control condition

Figure 1: Number of participants and dropout.

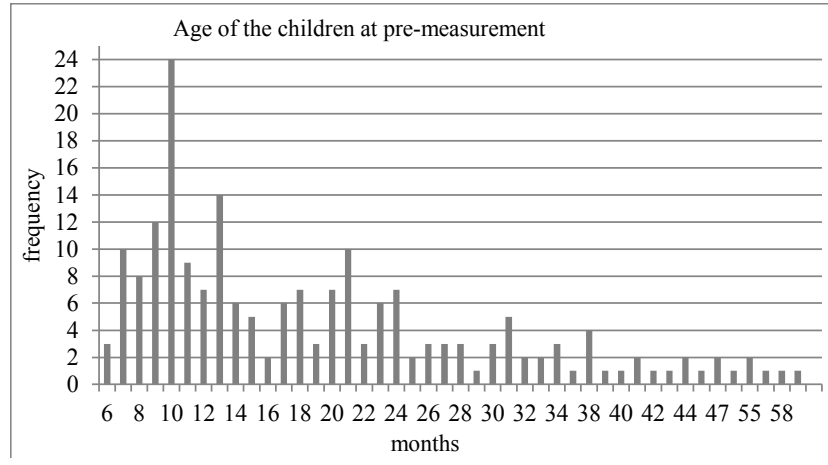

Figure 2: Age distribution of the children at pre-measurement.

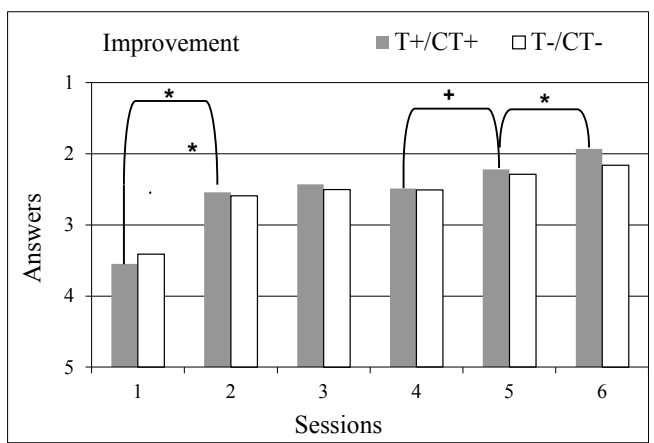

Note: Answers to the question "I have the feeling that the sleep situation of my child has improved" (1=completely applies to me: $2=$ rather applies to me: $3=1$ don't know: $4=$ rather doesn't apply to me: 5=doesn't apply to me at all). *: Significant differences after Bonferroni correction $(\alpha<0.0083)$; ${ }^{+}$: Trend for significance $(0.05 \leq p \geq 0.0083)$; $T+/ C T+$ : Treatment with personal assistance; T-/TC-: Treatment without personal assistance

Figure 3: Answers to question "improvement" of MKO-TEQ. lived with its biological mother and adoptive father (condition $\mathrm{T}+$ ), and one child lived with its foster parents (condition T-). In both latter cases, parents were advised to answer the questionnaires as if they were biological parents. Mothers in this sample were in mean 33.86 years of age $(S D=4.05)$, fathers were 36.89 years of age $(S D=5.79)$. For more information and distribution of these variables (Table 1).

Compared to the general population in Germany [61] parents in this sample were higher educated. $64 \%$ of mothers had a university degree (average Germany: $9.5 \%$ to $16.7 \%$ for people 25 to 55 years of age) and $59 \%$ of fathers had a university degree (average Germany: $9.6 \%$ to $12.6 \%$ for 25 to 55 years of age). Most of the mothers were currently intentionally unemployed (53\%) and fathers full-time employed (91\%). For more information and distribution of these variables (Table 2).

\section{Intervention and compliance}

The Mini-KiSS Online program contains six treatment sessions delivered weekly via the Internet. Each of these treatment sessions included modules of the Mini-KiSS Online manual, imaginative exercises such as audio files for the parents and bedtime stories for the child. Furthermore, the parents were instructed to buy a stuffed leopard as a sleep-assistance for the child. The manual was constructed as a bibliotherapeutic self-learning approach. It consisted of written information based on cognitive-behavioural and imaginative strategies (e.g. psychoeducation, sleep hygiene, learning behaviour of the child, token system, anxieties, defiantness, stress and relaxation of the parents, attentiveness, calmness, how to establish the stuffed leopard). For more details see Schlarb and Brandhorst [60].

Mini-KiSS Online was intended as a six week short-time intervention. Most of the families complied with this guideline. However, some families needed adjustment in their treatment schedule (33\%) mostly due to illness of the child or planned holidays. In mean, families required 46.7 days (range 39-77 days). Each week before the next treatment session parents were requested to return written exercises via e-mail. Thereby, we were able to monitor dropout and control active participation. Most of the families succeeded with this requirement $(75.8 \%)$. However, some families struggled and did not return some or all of the exercises (number of missing exercises: lack of 1 exercise - 9.3\%; \#2 - 2.6\%; \#3 - 3.6\%; \#4 - 2.1\%; \#5 - 3.6\%; \#6 - 3.1\%).

Parents in $\mathrm{T}+$ got six weekly telephone calls announced in their treatment schedule at the end of each treatment week. The telephone calls were performed by psychologists familiar with the Mini-KiSS Online manual who had been trained before. Content of the telephone call was documented by default. Parents used these telephone calls to ask questions, to be guided to their purpose, or to reduce feelings of insecurity with their purpose. The telephone calls lasted 10-15 minutes (session 1: $\mathrm{M}=13.2 \mathrm{~min}$ ( $\mathrm{SD} 3.2$ ); session 2: $\mathrm{M}=11.6 \mathrm{~min}$ (SD 3.4); session 3: $M=11.1 \mathrm{~min}$ ( $\mathrm{SD} 3.4$ ); session $4: \mathrm{M}=10.6 \mathrm{~min}$ ( $\mathrm{SD} 4.1$ ); session 5: $\mathrm{M}=10.8 \mathrm{~min}(\mathrm{SD} 4.2)$; session $6: \mathrm{M}=10.9 \mathrm{~min}$ ( $\mathrm{SD} 3.8)$ ).

Parents were recommended to perform the treatment sessions together. This recommendation was realized by only some parents. Mothers and fathers were separately asked who preferred to execute the Mini-KiSS Online training. Half of mothers (52\%) reported to have preferred executing the training alone ( $48 \%$ executed by parents together, $0 \%$ executed by father alone). Half of fathers (50\%) reported that the training was rather executed by the parents together $(48 \%$ executed by mothers alone, $2 \%$ executed by father alone).

\section{Measurements}

A sleep diary was used to investigate the following information 


\begin{tabular}{|c|c|c|c|c|c|c|}
\hline Age & Treatment & M & SD & Min & Max & $\mathbf{N}$ \\
\hline \multirow{3}{*}{ Child (month) } & $\mathrm{T}+$ & 18.11 & 10.50 & 7 & 59 & 72 \\
\hline & T- & 20.14 & 14.00 & 6 & 63 & 58 \\
\hline & C & 21.03 & 12.33 & 6 & 57 & 69 \\
\hline \multirow{3}{*}{ Mothers (years) } & $\mathrm{T}+$ & 33.54 & 4.01 & 23 & 42 & 71 \\
\hline & $\mathrm{T}-$ & 33.96 & 4.14 & 26 & 46 & 57 \\
\hline & $\mathrm{C}$ & 34.12 & 4.05 & 25 & 45 & 69 \\
\hline \multicolumn{6}{|c|}{ Missing values } & 2 \\
\hline \multirow{3}{*}{ Fathers (years) } & $\mathrm{T+}$ & 36.46 & 6.30 & 24 & 58 & 71 \\
\hline & T- & 37.22 & 5.29 & 28 & 51 & 54 \\
\hline & C & 37.09 & 5.66 & 25 & 54 & 64 \\
\hline \multicolumn{6}{|c|}{ Missing values } & 8 \\
\hline
\end{tabular}

Note: M: Mean; SD: Standard Deviation; T+: Treatment with personal assistance; T-: Treatment without personal assistance; C: Control condition Table 1: Age of children and their parents.

\begin{tabular}{|c|c|c|c|c|c|c|c|c|}
\hline \multirow[b]{2}{*}{ Highest education: \# } & \multicolumn{4}{|c|}{ Mothers } & \multicolumn{4}{|c|}{ Fathers } \\
\hline & Overall & $\mathrm{T}+$ & T- & $\mathrm{C}$ & Overall & $\mathrm{T}+$ & T- & C \\
\hline Secondary general school & 1 & 1 & 0 & 0 & 11 & 4 & 2 & 5 \\
\hline Intermediate school & 27 & 15 & 4 & 8 & 36 & 20 & 8 & 8 \\
\hline Grammar school* & 42 & 17 & 17 & 8 & 28 & 10 & 10 & 8 \\
\hline University $^{\star *}$ & 128 & 39 & 36 & 53 & 116 & 37 & 37 & 42 \\
\hline Other & 1 & 0 & 1 & 0 & 5 & 1 & 1 & 3 \\
\hline Missing values & - & - & - & - & 1 & - & - & 1 \\
\hline \multicolumn{9}{|l|}{ Employment: \# } \\
\hline Full time & 21 & 9 & 4 & 8 & 176 & 64 & 56 & 56 \\
\hline Part time & 68 & 24 & 18 & 26 & 10 & 3 & 1 & 6 \\
\hline Unemployed (intended) & 102 & 35 & 35 & 32 & 6 & 3 & 0 & 3 \\
\hline Unemployed (unintended) & 2 & 1 & 1 & 0 & 1 & 1 & 0 & 0 \\
\hline Missing values & 6 & 3 & - & 3 & 4 & 1 & 1 & 2 \\
\hline
\end{tabular}

Note: \#: Number of participants; T+: Treatment with personal assistance; T-: Treatment without personal assistance; C: Control condition; *: Including advanced technical college entrance qualification ("Fachhochschulreife"); ${ }^{* *}$ : Including conferral of a doctorate

Table 2: Education and employment of parents.

over a ten day period: time of going to bed, sleep onset latency, number and duration of night waking, nocturnal feeding, overall night time and daytime sleep, co-sleeping, waking time in the morning, use of medication, information about special events like illness and about sleep onset and sleep maintenance situation. Based on this information, sleep efficiency (ratio of minutes of sleep divided by the number of minutes in bed) and overall sleep duration were calculated. For sleep onset and sleep maintenance situation parents detailed if the child needed a baby bottle, breast feeding, cuddling or physical contact, swinging or rocking, carrying, presence of a parent, toy or stuffed animal, pacifier or thumb. Parents were requested not to start with the sleep diary in cases of illness or holiday.

The Mini-KiSS Online Anamnestic Questionnaire (MKO-AQ) investigated anamnestic and demographic information as well as information about family and sleep situation. It was divided into several sections: information about the child, family, sleep environment, sleep onset, night waking, waking in the morning, parental behaviour in these situations, daily behaviour of the child, recent life events, development, regulation and characteristics of the child. Additionally, parents were asked to rate the current sleep behaviour of their child on a ten-point Likert scale from one (completely normal) to ten (very problematic) ("How would you appraise the current sleep behaviour of your child?").

The Child Behavior Checklist 1.5-5 (CBCL 1.5-5) from the ASEBA (Achenbach System of Empirically Based Assessment) [62] was used to assess children's sleep behavior. It consists of six T-standardized syndrome scales (not described here) plus the "sleep problems" subscale. The cut-off point for normal range is a $\mathrm{T}$ score $<65$, the borderline range is from 65 to 69 , and the clinical range is $\geq 70$. The age range from the CBCL 1.5-5 was extended for children younger than 18 months.

The Mini-KiSS Online Treatment Evaluation Questionnaire (MKO-TEQ) was added to the treatment exercises which were returned weekly by the parents to evaluate session specific acceptance and utility of all contents of the Mini-KiSS Online treatment (for T+: return prior to phone call). Parents rated on a five-point Likert scale (1=was completely helpful for me; $2=$ was rather helpful for me; $3=I$ do not know; $4=$ was rather not helpful for me; $5=$ was not at all helpful for me). All six sessions were evaluated at the end of the treatment week with a varying number of questions (session one to six: $6-16-11$ $12-13-6$ questions). Parents in T+ answered the MKO-TEQ before the telephone call of the treatment week. Additionally, we asked for an overall treatment evaluation and for subjective rating of improvement of the sleep problem ( $1=$ completely applies to me; $2=$ rather applies to me; $3=I$ don't know; $4=$ rather doesn't apply to me; $5=$ doesn't apply to me at all). Furthermore, the MKO-TEQ contained a free comment field at the end of the questionnaire.

\section{Diagnosis of sleep problems}

Diagnosis of sleep disorders was based on criteria of Gaylor et al. [63] (Table 3). However, in our sample some difficulties appeared using Gaylor's criteria while nearly no parent reported "reunions" 
after having brought their child to bed. Furthermore, criteria needed to be expanded for children younger than 12 months of age. Hence, diagnoses of sleep onset dysomnia were solely based on sleep onset latency and parental assistance (Table 4). As can be seen, the most frequent combination is sleep onset disturbance and sleep maintenance disorder (17.1\%). Additionally, many parents reported either the need of parental assistance OR sleep onset latency, but not both. According to Gaylor, these families fail criteria for sleep onset dysomnia but according to DSM-5 criteria, these children would fulfil criteria of insomnia. So we additionally examined the single appearance of either parental assistance or extended sleep onset latency (Table 5). It becomes apparent that most children basically have problems sleeping without their parents independent of sleep onset latency. Only eight children neither had parental assistance nor extended sleep onset latency.

\section{Sample characteristics and statistical analysis}

All data analyses were performed using the PASW (v 22.0; SPSS Inc, Chicago, IL). Intent-to-treat method (as recommended by Griffiths \& Christensen in their review) [57] which was used to avoid increase of probability of type I errors and to obtain complete data on all subjects. This means that we assumed that non-completers did not make any improvements and therefore were not willing to fill in the post-measurement. Baseline comparisons for parents completing postmeasurement vs. non-completers yielded no differences with t-test or Mann-Whitney test (for age of child/parents, child gender, subjective global sleep rating of $\mathrm{MKO}-\mathrm{AQ}$, diagnosis according to Gaylor, education and employment of parents). For missing data at 3-month follow-up, Last-Observation-Carried-Forward was used [64].

Initial group differences were calculated with analysis of variance
(ANOVA) for metric values and the Kruskal-Wallis test for nonmetric values for all demographics and outcome variables. None of the comparisons was significant with regard to Gaylor's diagnosis of sleep maintenance dysomnia $(\mathrm{p}=0.022 ; \mathrm{T}+\mathrm{MD}=3 ; \mathrm{T}-\mathrm{MD}=4 ; \mathrm{C} \mathrm{MD}=3)$ and education for fathers ( $\mathrm{p}=0.021$, Table 2$)$.

Data of sleep diary: A maximum of three single days were excluded if illness, teething or use of medication influencing sleep was reported. Further days were excluded if parents reported special events in combination with discrepant data compared to the other days (e.g. inoculation, overnight stays). If there were more than three days to exclude, the sleep diary was treated as missing. If parents reported that their child sleeps in a bedside cot, it was not rated as co-sleeping. Intent-to-treat method between pre- and post-measurement was used for five cases in $\mathrm{T}+, 12$ cases in T- and five cases in C. Between postmeasurement and follow-up it was used for 13 cases in $\mathrm{T}+$ and 18 cases in T-. Usually all ten days of the sleep diary were used for analysis.

Because of sufficient sample size $(\mathrm{N}$ per cell $>50)$ and robustness of analysis used here, normal distribution was assumed [65]. Overall, significance level was $\alpha=5 \%$. Partial eta squared was used to demonstrate effect size [66]. Treatment acceptance was analysed with Friedman's test and Wilcoxon test for within-group differences and MannWhitney test for between group differences due to ordinal scale of data. To analyse data of children's sleep, parental involvement, parental psychological strain, parental sleep related self-efficacy, and parental coping-strategies, we used repeated measure ANOVA. Relevant post analyses were performed with pairwise t-tests. To counteract the problem of multiple comparisons, Bonferroni-Holm method was used to define new significance levels for t-tests. The final correlations were performed with Pearson's product-moment correlation after visual

\begin{tabular}{|c|c|c|}
\hline No. & Sleep onset dysomnia ( 2 of the following 3 criteria are needed) & Sleep maintenance dysomnia \\
\hline 1 & Sleep onset latency of more than 20 minutes ( $12-23$ month of age) or 30 minutes ( $\geq 24$ month) & $\begin{array}{c}\geq 2 \text { (12-23 months of age) or } \geq 1 \text { ( } \geq 24 \text { month) } \\
\text { awakenings per night }\end{array}$ \\
\hline 2 & Parent remain in room for sleep-onset & Total length of awakening of minimum 20 minutes. \\
\hline 3 & More than two reunions & - \\
\hline
\end{tabular}

Note: Symptoms need to be stable over at least 1 month. Severity is distinguished through frequency: pertubation=1 episode per week; disturbance=2-4 episodes per week; disorder $=5-7$ episodes per week

Table 3: Criteria according to Gaylor et al. [63].

\begin{tabular}{|c|c|c|c|c|}
\hline \multirow{2}{*}{$\begin{array}{c}\text { Sleep onset dysomnia } \\
\text { \# (\%) }\end{array}$} & \multicolumn{4}{|c|}{ Sleep maintenance dysomnia } \\
\cline { 2 - 5 } & None & Pertu-bation & Distur-bance & Disorder \\
\hline None & $16(8)$ & $6(3)$ & $15(7.5)$ & $29(14.6)$ \\
\hline Pertubation & $4(2)$ & $5(2.5)$ & $7(3.5)$ & $12(6)$ \\
\hline Disturbance & $11(5.5)$ & $5(2.5)$ & $18(9)$ & $34(17.1)$ \\
\hline Disorder & $7(3.5)$ & $3(1.5)$ & $12(6)$ & $15(7.5)$ \\
\hline
\end{tabular}

Note: Frequency of combinations of sleep onset and sleep maintenance dysomnia according to Gaylor et al. [63] based on sleep diary. \#: Number of diagnosis

Table 4: Diagnoses according to Gaylor [63].

\begin{tabular}{|c|c|c|c|}
\hline \multirow{2}{*}{$\begin{array}{c}\text { Sleep onset latency } \\
\#(\%)\end{array}$} & \multicolumn{3}{|c|}{ Parental assistance to fall asleep } \\
\cline { 2 - 4 } & None & Pertu-bation & Distur-bance \\
\hline None & $8(4)$ & $2(1)$ & $3(1.5)$ \\
\hline Pertubation & $2(1)$ & $3(1.5)$ & $2(1)$ \\
\hline Disturbance & $9(4.5)$ & $1(0.5)$ & $4(2)$ \\
\hline Disorder & $5(2.5)$ & $1(0.5)$ & $4(9.5)$ \\
\hline
\end{tabular}

Note: Frequency of combinations of sleeps onset problems in consideration of parental assistance OR sleep onset latency in the evening based on sleep diary. \#: Number of diagnosis

Table 5: Diagnoses based on sleep onset latency or parental presence. 
check of linearity with scatterplot.

\section{Results}

\section{Acceptance of Mini-KiSS online}

We expected that parents would accept the Mini-KiSS Online training and that there would be an advantage for parents participating in the treatment condition with personal support. Therefore, the MKOTEQ was used to measure acceptance and perceived utility. Information from 106 data-sets was used from $\mathrm{T}+$ and $\mathrm{CT}+(=\mathrm{C}$ randomly assigned to $\mathrm{T}+$ after waiting time) to evaluate treatment with personal assistance. Furthermore, 93 data-sets from T- and CT- $(=\mathrm{C}$ randomly assigned to $\mathrm{T}$ - after waiting time) were used to evaluate treatment without personal assistance.

At the end of the last practice week, parents of both conditions $(\mathrm{T}+/$ $\mathrm{CT}+$ and T-/CT-) valued the Mini-KiSS Online training as helpful in improving the child's sleep behaviour, and stated they were glad to have participated, would recommend the Online training to other families, claimed to have been encouraged and not set under pressure by the Online training, and to have coped well with the temporal organization (Table 6). Some of these statements were rated significantly more positively by $\mathrm{T}+/ \mathrm{CT}+$ than by $\mathrm{T}-/ \mathrm{CT}-$.

Furthermore, parents evaluated four statements weekly after each training session regarding "Attractiveness" of the training ("The topics of the last treatment session appealed to me"; $\mathrm{T}+/ \mathrm{CT}+\mathrm{MD}=2$; $\mathrm{T}-/$ CT-: $\mathrm{MD}=2$ ), "Generalization" of the content ("I was able to transfer the general information to my personal situation"; $\mathrm{T}+/ \mathrm{CT}+\mathrm{MD}=2$; T-/CT-: $M D=2$ ) and the "Motivation" of the training ("The last online session motivated me to continue working on the sleep problem of my child"; $\mathrm{T}+/ \mathrm{CT}+: \mathrm{MD}=2$; T-/CT-: $\mathrm{MD}=2$ ). Comparisons between the groups showed just a tendency for "Attractiveness" in session $6(\mathrm{Z}=-$ 2.60, $\mathrm{p}=0.009)$, for "Motivation" in session $4(\mathrm{Z}=-2.22, \mathrm{p}=0.026)$, and for "Motivation" in session $6(\mathrm{Z}=-2.28, \mathrm{p}=0.023)$. For these last results, parents of $\mathrm{T}+/ \mathrm{CT}+$ seemed to be more attracted and motivated by the treatment in the mentioned sessions.
Finally, parents of $\mathrm{T}+/ \mathrm{C}+$ were asked to rate if "The personal contact to the trainer was very important for the success of the training". $92 \%$ of the parents rated this item with "completely" or "rather applies to me" $(\mathrm{MD}=1, \mathrm{SD}=0.82)$. Additionally, parents of $\mathrm{T}-/ \mathrm{C}$ - were asked to rate if "The personal contact to a trainer would have been very important to me". $69 \%$ of the parents rated this item with "completely" or "rather applies to me", $18 \%$ stated "I do not know" and 13\% rated this item as "rather doesn't apply to me" or "doesn't apply to me at all" ( $\mathrm{MD}=2$, $\mathrm{SD}=1.16$ ).

\section{Child's sleep}

We expected to find improvements in both treatment conditions (without advantage for $\mathrm{T}+$ ) while no change was anticipated for the control condition. Therefore, the sleep diaries were used as measurement to survey treatment efficacy. As more global and subjective variables, we used the subscale "sleep problems" from the CBCL 1.5-5 and the rating of "Current sleep behaviour" from MKO-AQ. Mean values are presented in Table 7 and the results in Table 8.

Sleep onset latency: The interaction term time ${ }^{\star}$ group of pre-post comparison indicated significant treatment effects. T-tests revealed that participation in both treatments resulted in significant reduction of sleep onset latency while there was no change in the control condition. Thereby, there was no advantage for T+. Follow-up comparisons indicated stability of these effects for both treatment conditions (Figure $4)$.

Frequency and duration of night waking: Results for pre-post comparison showed reduction of frequency and duration of night waking irrespective of condition affiliation. However, even though t-tests did not find differences between the conditions for duration of night waking, there was a significant interaction term indicating an advantage for the treatment conditions. Follow-up data showed no further change of these values after three months (Figure 5).

Sleep efficiency: The interaction term time* group of pre-post comparison indicated significant treatment effects. For all conditions, sleep efficiency increased with time. But $\mathrm{T}+$ and $\mathrm{T}$ - showed a

\begin{tabular}{|r|c|c|}
\hline \multicolumn{1}{|c|}{ Item } & $\begin{array}{c}\text { T+/CT+ } \\
\text { MD (SD) }\end{array}$ & $\begin{array}{c}\text { T-/CT- } \\
\text { MD (SD) }\end{array}$ \\
\hline "The Online training helped me to better understand the sleep behavior of my \\
child."
\end{tabular}

Note: Answer categories: 1 = completely applies to me: 2 = rather applies to me: $3=$ I don't know: $4=$ rather doesn't apply to me: $5=$ doesn't apply to me at all. MD: Median; SD: Standard deviation; bold: Significant value

Table 6: Global statements regarding the entire treatment.

\begin{tabular}{|c|c|c|c|c|c|c|c|c|}
\hline \multirow{2}{*}{$\begin{array}{l}\text { Mean values of } \\
\text { main outcome }\end{array}$} & \multicolumn{3}{|c|}{ pre } & \multicolumn{3}{|c|}{ post } & \multicolumn{2}{|c|}{ follow-up } \\
\hline & $\begin{array}{c}\text { T+ } \\
M(S D)\end{array}$ & $\begin{array}{c}\text { T- } \\
M(S D)\end{array}$ & $\begin{array}{c}\text { C } \\
M(S D)\end{array}$ & $\begin{array}{c}\mathrm{T}+ \\
\mathrm{M}(\mathrm{SD})\end{array}$ & $\begin{array}{c}\text { T- } \\
M(S D)\end{array}$ & $\begin{array}{c}\text { C } \\
M(S D)\end{array}$ & $\begin{array}{c}\mathbf{T +} \\
\mathrm{M}(\mathrm{SD})\end{array}$ & $\begin{array}{c}\text { T- } \\
M(S D)\end{array}$ \\
\hline $\begin{array}{l}\text { Sleep onset latency } \\
\text { (in minutes) }\end{array}$ & $22.97(13.13)$ & $27.95(20.49)$ & $23.43(15.12)$ & $\begin{array}{l}15.32 \\
(9.95)\end{array}$ & $\begin{array}{c}21.71 \\
(18.41)\end{array}$ & $\begin{array}{c}23.65 \\
(13.76)\end{array}$ & $\begin{array}{c}15.06 \\
(11.25)\end{array}$ & $\begin{array}{c}20.50 \\
(12.73)\end{array}$ \\
\hline $\begin{array}{l}\text { Relative frequency of night waking } \\
\text { (\# per night) }\end{array}$ & $2.92(1.67)$ & $3.29(2.40)$ & $3.46(2.27)$ & $1.96(1.38)$ & $\begin{array}{l}2.12 \\
(2.01)\end{array}$ & $2.85(2.34)$ & $\begin{array}{c}1.69 \\
(1.31)\end{array}$ & $\begin{array}{c}1.95 \\
(1.96)\end{array}$ \\
\hline $\begin{array}{l}\text { Relative duration of night waking } \\
\text { (in minutes per night) }\end{array}$ & $29.38(22.55)$ & $34.40(26.31)$ & $29.81(26.92)$ & $15.60(16.34)$ & $19.08(20.91)$ & $23.03(22.37)$ & $\begin{array}{c}12.72 \\
(16.96)\end{array}$ & $\begin{array}{c}18.96 \\
(22.91)\end{array}$ \\
\hline
\end{tabular}


Citation: Schlarb AA, Brandhorst I, Peters E, Hautzinger M (2018) Telephone Support in an Internet-Based Treatment for Sleep Problems in Early Childhood. J Psychiatry 21: 435. doi:10.4172/2378-5756.1000435

Page 7 of 14

\begin{tabular}{|c|c|c|c|c|c|c|c|c|}
\hline $\begin{array}{l}\text { Sleep efficiency } \\
\text { (in \%) }\end{array}$ & $89.57(4.60)$ & $88.84(5.07)$ & $89.81(4.46)$ & $93.27(3.64)$ & $92.06(5.45)$ & $91.24(4.25)$ & $\begin{array}{l}94.02 \\
(3.87)\end{array}$ & $\begin{array}{l}92.15 \\
(5.09)\end{array}$ \\
\hline $\begin{array}{l}\text { 24h sleep duration } \\
\text { (in minutes) }\end{array}$ & $711.46(44.48)$ & $\begin{array}{l}699.49 \\
(49.01)\end{array}$ & $\begin{array}{l}700.71 \\
(43.63)\end{array}$ & $\begin{array}{l}727.23 \\
(50.94)\end{array}$ & $\begin{array}{l}712.73 \\
(55.17)\end{array}$ & $\begin{array}{l}699.80 \\
(49.56)\end{array}$ & $\begin{array}{l}726.60 \\
(49.52)\end{array}$ & $\begin{array}{l}708.49 \\
(52.33)\end{array}$ \\
\hline $\begin{array}{l}\text { Subscale "sleep problems" } \\
\text { (CBCL 1.5-5) }\end{array}$ & $7.00(2.10)$ & $\begin{array}{c}7.22 \\
(2.17)\end{array}$ & $\begin{array}{c}6.51 \\
(2.17)\end{array}$ & $\begin{array}{c}3.92 \\
(2.73)\end{array}$ & $\begin{array}{c}4.50 \\
(2.68)\end{array}$ & $\begin{array}{l}6.17 \\
(2.40)\end{array}$ & $\begin{array}{l}3.47 \\
(2.61)\end{array}$ & $\begin{array}{c}4.19 \\
(2.91)\end{array}$ \\
\hline $\begin{array}{l}\text { "Current sleep behavior" } \\
(\text { MKO-AQ)* }\end{array}$ & $\begin{array}{c}7.56 \\
(1.47)\end{array}$ & $\begin{array}{c}7.69 \\
(1.68)\end{array}$ & $\begin{array}{c}7.35 \\
(1.50)\end{array}$ & $\begin{array}{l}4.04 \\
(2.18)\end{array}$ & $\begin{array}{c}5.24 \\
(2.53)\end{array}$ & $\begin{array}{c}6.41 \\
(2.24)\end{array}$ & $\begin{array}{l}4.07 \\
(2.20)\end{array}$ & $\begin{array}{c}5.10 \\
(2.77)\end{array}$ \\
\hline
\end{tabular}

Note: Date of post-measurement and follow-up include last-observation-carried-forward method. M: Mean; SD: Standard Deviation; \#: Number; T+: Treatment with personal assistance; T-: Treatment without personal assistance; C: Control condition; *: Answers to the rating of "Current sleep behavior" of Mini-KiSS Online Anamnestic Questionnaire (MKO-AQ) vary on a ten-point Likert scale from one (completely normal) to ten (very problematic); CBCL 1.5-5: Child Behavior Checklist 1.5-5

Table 7: Mean and standard deviations for sleep diary: CBCL 1.5-5: and MKO-AQ.

\begin{tabular}{|c|c|c|c|c|c|c|c|c|c|c|c|}
\hline \multirow[t]{2}{*}{ Efficacy measures } & \multirow[t]{2}{*}{ Results } & \multicolumn{2}{|c|}{$\begin{array}{l}\text { Interaction effects: } \\
\text { time*group }\end{array}$} & \multicolumn{2}{|c|}{$\begin{array}{l}\text { Main effects: } \\
\text { time / group }\end{array}$} & \multicolumn{3}{|c|}{$\begin{array}{c}\text { Time comparisons*: } \\
\text { pre vs. post / post vs. follow- } \\
\text { up }\end{array}$} & \multicolumn{3}{|c|}{$\begin{array}{l}\text { Group comparison of pre-post } \\
\text { or post-follow-up differences }\end{array}$} \\
\hline & & p-/F-value & $\begin{array}{c}\text { partial } \\
\text { eta }^{2}\end{array}$ & $p$-value & partial eta ${ }^{2}$ & $\mathrm{~T}+$ & T- & C & $\begin{array}{l}\text { DT+ vs. } \\
\text { DT- }\end{array}$ & $\begin{array}{l}\text { DT+ vs. } \\
\text { DC }\end{array}$ & $\begin{array}{l}\text { DT- vs. } \\
\text { DC }\end{array}$ \\
\hline \multirow{2}{*}{ Sleep onset latency } & $\begin{array}{l}\text { pre vs. } \\
\text { post }\end{array}$ & $\begin{array}{c}F(2: 194)=7.31 \\
p \leq 0.001\end{array}$ & 0.070 & $\begin{array}{l}\text { time: } p \leq 0.001 \\
\text { group: } p=0.048\end{array}$ & $\begin{array}{l}0.112 \\
0.031\end{array}$ & $\begin{array}{c}t=4.41 \\
p \leq 0.001\end{array}$ & $\begin{array}{c}t=3.52 \\
p \leq 0.001\end{array}$ & $\begin{array}{l}t=-0.18 \\
p=0.861\end{array}$ & $\begin{array}{l}t=-0.58 \\
p=0.565\end{array}$ & $\begin{array}{l}t=-3.71 \\
p \leq 0.001\end{array}$ & $\begin{array}{l}t=-2.99 \\
p=0.003\end{array}$ \\
\hline & $\begin{array}{l}\text { post vs. } \\
\text { follow-up }\end{array}$ & $\begin{array}{c}F(1: 126)=0.18 \\
p=0.675\end{array}$ & 0.001 & $\begin{array}{l}\text { time: } p=0.495 \\
\text { group: } p=0.006\end{array}$ & $\begin{array}{l}0.004 \\
0.059\end{array}$ & & & & & & \\
\hline \multirow{2}{*}{$\begin{array}{l}\text { Relative frequency } \\
\text { of night waking }\end{array}$} & $\begin{array}{l}\text { pre vs. } \\
\text { post }\end{array}$ & $\begin{array}{c}F(2: 195)=2.63 \\
p=0.74\end{array}$ & 0.026 & $\begin{array}{l}\text { time: } p \leq 0.001 \\
\text { group: } p=0.082\end{array}$ & $\begin{array}{l}0.301 \\
0.025\end{array}$ & $\begin{array}{c}t=6.42 \\
p \leq 0.001\end{array}$ & $\begin{array}{l}t=5.39 \\
p \leq 0.001\end{array}$ & $\begin{array}{c}t=3.88 \\
p \leq 0.001\end{array}$ & $\begin{array}{c}t=0.78 \\
p=0.437\end{array}$ & $\begin{array}{l}t=-1.65 \\
p=0.100\end{array}$ & $\begin{array}{l}t=-2.14 \\
p=0.035\end{array}$ \\
\hline & $\begin{array}{l}\text { post vs. } \\
\text { follow-up }\end{array}$ & $\begin{array}{c}F(1: 127)=0.41 \\
p=0.523\end{array}$ & 0.003 & $\begin{array}{l}\text { time: } p=0.006 \\
\text { group: } p=0.449\end{array}$ & $\begin{array}{l}0.059 \\
0.005\end{array}$ & $\begin{aligned} t & =2.76 \\
p & =0.007\end{aligned}$ & $\begin{array}{l}t=1.36 \\
p=0.180\end{array}$ & & & & \\
\hline \multirow{2}{*}{$\begin{array}{l}\text { Relative duration of } \\
\text { night waking }\end{array}$} & $\begin{array}{l}\text { pre vs. } \\
\text { post }\end{array}$ & $\begin{array}{c}F(2: 195)=3.36 \\
p=0.037\end{array}$ & 0.033 & $\begin{array}{l}\text { time: } p \leq 0.001 \\
\text { group: } p=0.401\end{array}$ & $\begin{array}{l}0.262 \\
0.009\end{array}$ & $\begin{aligned} t & =5.75 \\
p & \leq 0.001\end{aligned}$ & $\begin{aligned} t & =4.98 \\
p & \leq 0.001\end{aligned}$ & $\begin{array}{l}t=3.32 \\
p \leq \\
0.001\end{array}$ & $\begin{array}{c}t=0.40 \\
p=0.688\end{array}$ & $\begin{array}{l}t=-2.21 \\
p=0.029\end{array}$ & $\begin{array}{l}t=-2.38 \\
p=0.019\end{array}$ \\
\hline & $\begin{array}{l}\text { post vs. } \\
\text { follow-up }\end{array}$ & $\begin{array}{c}F(1: 127)=0.91 \\
p=0.341\end{array}$ & 0.007 & $\begin{array}{l}\text { time: } p=0.300 \\
\text { group: } p=0.116\end{array}$ & $\begin{array}{l}0.008 \\
0.019\end{array}$ & & & & & & \\
\hline \multirow{2}{*}{$\begin{array}{l}\text { Sleep } \\
\text { efficiency }\end{array}$} & $\begin{array}{l}\text { pre vs. } \\
\text { post }\end{array}$ & $\begin{array}{c}F(2: 192)=8.02 \\
p \leq 0.001\end{array}$ & 0.077 & $\begin{array}{l}\text { time: } p \leq 0.001 \\
\text { group: } p=0.279\end{array}$ & $\begin{array}{l}0.354 \\
0.013\end{array}$ & $\begin{array}{l}t=-7.92 \\
p \leq 0.001\end{array}$ & $\begin{array}{l}t=-6.05 \\
p \leq 0.001\end{array}$ & $\begin{array}{c}t=-3.34 \\
p \leq \\
0.001\end{array}$ & $\begin{array}{c}t=0.55 \\
p=0.581\end{array}$ & $\begin{aligned} t & =3.94 \\
p & \leq 0.001\end{aligned}$ & $\begin{array}{c}t=3.08 \\
p=0.003\end{array}$ \\
\hline & $\begin{array}{l}\text { post vs. } \\
\text { follow-up }\end{array}$ & $\begin{array}{c}F(1: 126)=1.44 \\
p=0.233\end{array}$ & 0.011 & $\begin{array}{l}\text { time: } p=0.254 \\
\text { group: } p=0.031\end{array}$ & $\begin{array}{l}0.010 \\
0.036\end{array}$ & & & & & & \\
\hline \multirow{2}{*}{$24 \mathrm{~h}$ sleep duration } & $\begin{array}{l}\text { pre vs. } \\
\text { post }\end{array}$ & $\begin{array}{c}F(2: 191)=4.69 \\
p=0.010\end{array}$ & 0.047 & $\begin{array}{l}\text { time: } p \leq 0.001 \\
\text { group: } p=0.040\end{array}$ & $\begin{array}{l}0.053 \\
0.033\end{array}$ & $\begin{array}{c}t=-3.63 \\
p \leq 0.001\end{array}$ & $\begin{array}{c}t=-2.53 \\
p=0.014\end{array}$ & $\begin{array}{c}t=0.56 \\
p=0.581\end{array}$ & $\begin{aligned} t & =0.47 \\
p & =0.643\end{aligned}$ & $\begin{array}{c}t=2.93 \\
p=0.004\end{array}$ & $\begin{array}{c}t=2.27 \\
p=0.025\end{array}$ \\
\hline & $\begin{array}{l}\text { post vs. } \\
\text { follow-up }\end{array}$ & $\begin{array}{c}F(1: 25)=0.07 \\
p=0.798\end{array}$ & 0.001 & $\begin{array}{l}\text { time: } p=0.375 \\
\text { group: } p=0.035\end{array}$ & $\begin{array}{l}0.006 \\
0.035\end{array}$ & & & & & & \\
\hline \multirow{2}{*}{$\begin{array}{l}\text { CBCL: Subscale } \\
\text { "sleep problems" }\end{array}$} & $\begin{array}{l}\text { pre vs. } \\
\text { post- }^{-}\end{array}$ & $\begin{array}{c}F(2: 196)=22.99 \\
p \leq 0.001\end{array}$ & 0.190 & $\begin{array}{l}\text { time: } p \leq 0.001 \\
\text { group: } p=0.035\end{array}$ & $\begin{array}{l}0.388 \\
0.034\end{array}$ & $\begin{aligned} t & =9.19 \\
p & \leq 0.001\end{aligned}$ & $\begin{array}{c}t=7.26 \\
p \leq 0.001\end{array}$ & $\begin{array}{c}t=1.40 \\
p=0.166\end{array}$ & $\begin{array}{l}t=-0.71 \\
p=0.477\end{array}$ & $\begin{array}{l}t=-6.69 \\
p \leq 0.001\end{array}$ & $\begin{array}{l}t=-5.38 \\
p \leq 0.001\end{array}$ \\
\hline & $\begin{array}{l}\text { post vs. } \\
\text { follow-up }\end{array}$ & $\begin{array}{c}F(1: 128)=0.18 \\
p=0.722\end{array}$ & 0.001 & $\begin{array}{l}\text { time: } 0=0.047 \\
\text { group: } p=0.144\end{array}$ & $\begin{array}{l}0.031 \\
0.017\end{array}$ & $\begin{array}{c}t=1.77 \\
p=0.082\end{array}$ & $\begin{array}{c}t=1.11 \\
p=0.270\end{array}$ & & & & \\
\hline \multirow{2}{*}{$\begin{array}{l}\text { "Current sleep } \\
\text { behavior" rating }\end{array}$} & $\begin{array}{c}\text { pre vs. } \\
\text { post }\end{array}$ & $\begin{array}{c}F(2: 196)=22.99 \\
p \leq 0.001\end{array}$ & 0.190 & $\begin{array}{l}\text { time: } p \leq 0.001 \\
\text { group: } p \leq 0.001\end{array}$ & $\begin{array}{l}0.511 \\
0.076\end{array}$ & $\begin{array}{c}t=12.69 \\
p \leq 0.001\end{array}$ & $\begin{array}{c}t=8.21 \\
p \leq 0.001\end{array}$ & $\begin{array}{l}t=3.64 \\
p \leq \\
0.001\end{array}$ & $\begin{array}{l}t=-2.61 \\
p=0.010\end{array}$ & $\begin{array}{c}t=-6.78 \\
p \leq 0.001\end{array}$ & $\begin{array}{c}t=-3.83 \\
p \leq 0.001\end{array}$ \\
\hline & $\begin{array}{l}\text { post vs. } \\
\text { follow-up }\end{array}$ & $\begin{array}{c}F(1: 128)=0.31 \\
p=0.581\end{array}$ & 0.002 & $\begin{array}{l}\text { time: } p=0.714 \\
\text { group: } p=0.006\end{array}$ & $\begin{array}{l}0.001 \\
0.058\end{array}$ & & & & & & \\
\hline
\end{tabular}

Note: Analysis of pre and post data include all three groups (T+: T-: C) while comparison of follow-up data is based on post- and follow-up-values of T+ and T- only. Data of post-measurement and follow-up include values from last-observation carried-forward. T+: Treatment with personal assistance; T-: Treatment without personal assistance; C: Control condition; DT+: Difference in T+ between pre- and post-measurement; DT-: Difference in T- between pre- and post-measurement; DC: Difference in C between pre- and post-measurement; bold: Significant value (after Bonferroni-Holm correction for all t-tests); *: T-tests were only performed in case of significant interaction effect or significant main effect of time; ${ }^{* *}$ : T-tests were only performed in case of (almost) significant

Table 8: Results for sleep diary: CBCL 1.5-5: MKO-AQ.

significantly higher increase compared to C. No differences were found between $\mathrm{T}+$ and T-. Follow-up calculations showed no further increase after three months (Figure 6).
24 hrs.' sleep duration: The significant interaction effect for prepost comparison indicated treatment effects. While there was no change in $24 \mathrm{hrs} \mathrm{sleep} \mathrm{duration} \mathrm{in} \mathrm{C,} \mathrm{treatment} \mathrm{condition} \mathrm{T}+$ showed a marked 


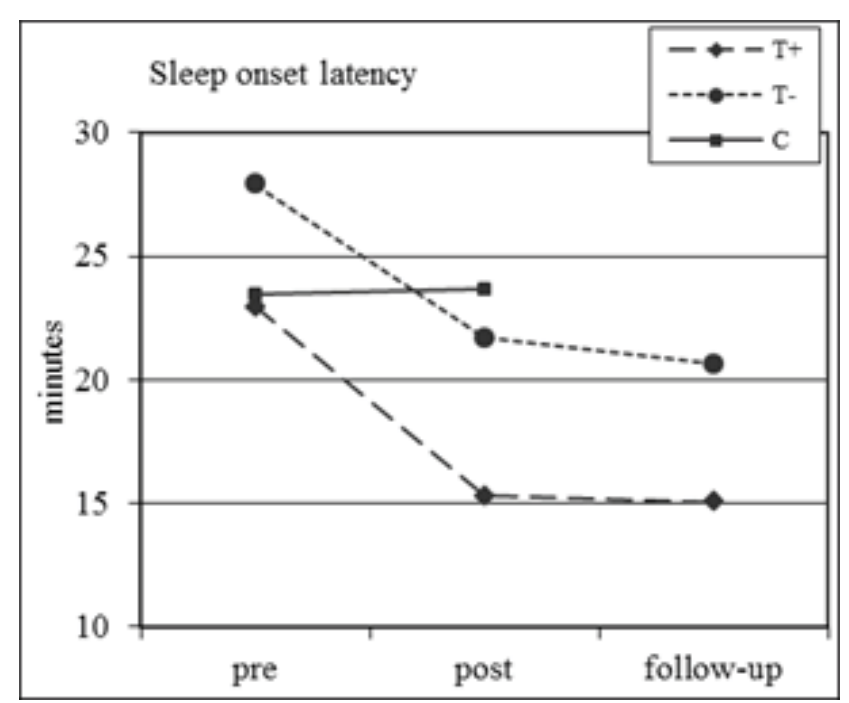

Figure 4: Sleep onset latency.
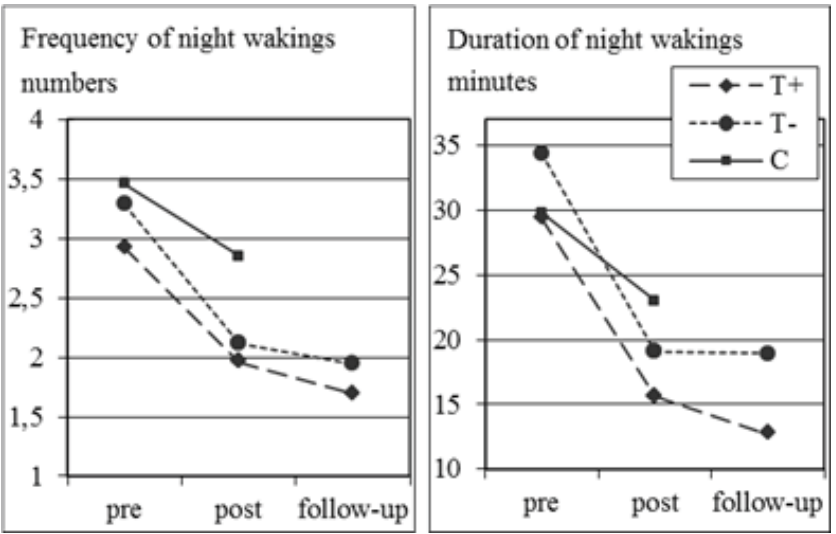

Figure 5: Relative frequency and duration of night waking

increase. However, diagrammed increase of T- did not reach statistical significance after Bonferroni-holm adjustment $(\alpha=0.012)$. The same was observed for comparison of T- and C differences $(\alpha=0.016)$. Again, there was no advantage for $\mathrm{T}+$ compared to $\mathrm{T}$ - for pre-post comparison. Follow-up evaluation showed stability of these effects with advantage for T+ compared to T- (Figure 7).

Subscale "sleep problems" (CBCL 1.5-5): This more global and subjective scale showed clear treatment effects for pre-post comparison. While there were significant improvements in $\mathrm{T}+$ and $\mathrm{T}-$-, there was no change in C. Again, no benefit of T+ compared to T- was found. However, children of $\mathrm{T}+$ tended to further decrease in the sleep subscale at 3-month follow-up while children of T- did not change (Figure 8).

"Current sleep behavior" (MKO-AQ): The current sleep behaviour was subjectively rated on a ten-point Likert scale from one (completely normal) to ten (very problematic). Results showed significant reduction of this rating for all three conditions for pre-post comparison. Thereby, $\mathrm{T}+$ showed the highest reduction followed by $\mathrm{T}$ - followed by $\mathrm{C}$. All these between-group comparisons reached statistical significance. These results were reflected in a highly significant time ${ }^{*}$ group interaction term. For the first time T+ showed advantage compared to T-. Followup data indicated no further changes for both conditions after three months (Figure 9).

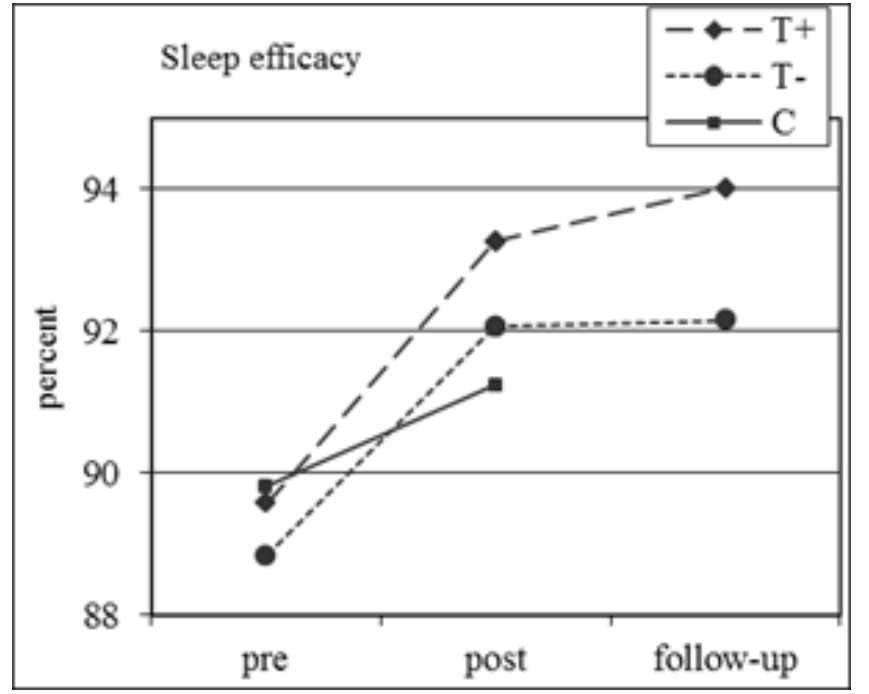

Figure 6: Sleep efficiency.

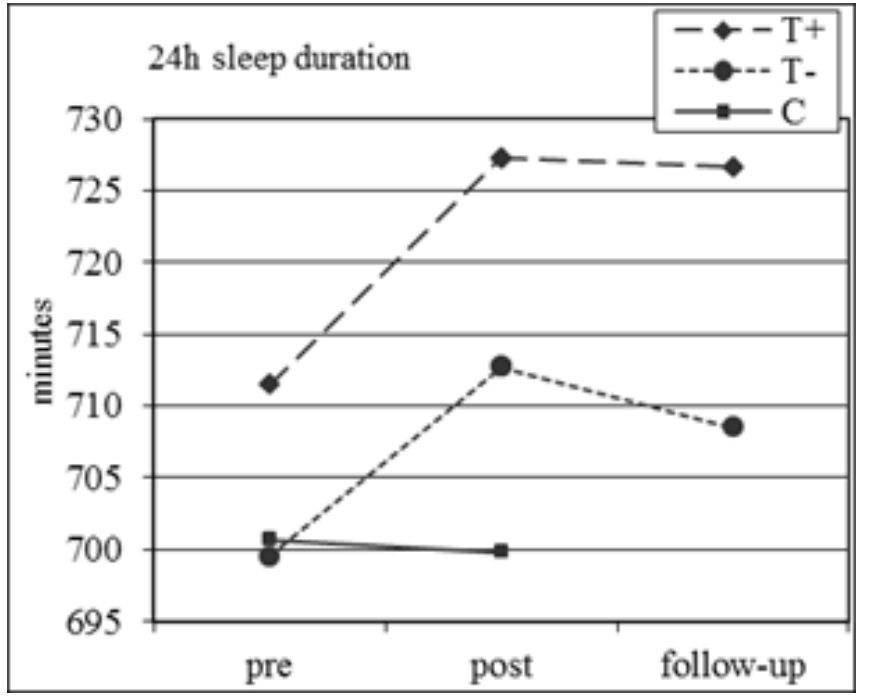

Figure 7: 24 h sleep duration.

Pre- vs. follow-up comparisons: To clarify, not only stability of effects (post vs. follow-up) but existence of positive treatment outcomes between pre- and follow-up measurement additional analysis were performed for $\mathrm{T}+$ and $\mathrm{T}-$. Altogether, analyses of variance confirmed the former results. Significant time effects (non-significant interaction or group effect) were found for frequency and duration of night waking, sleep efficiency, and subscale "sleep problems" of CBCL 1.5-5. Similarly, significant time and group effects (non-significant interaction effect) were found for sleep onset latency and $24 \mathrm{hr}$ sleep duration. As presented in the previous results, parents of $\mathrm{T}+$ and $\mathrm{T}$ - showed different ratings in their "current sleep behaviour" of MKO-AQ presenting not only significant time and group effects, but also significant interaction term.

MKO-TEQ: Finally, we used the statement "I have the feeling that the sleep situation of my child has improved" from weekly MKO-TEQ to have a look at the development of subjectively perceived improvement over the six treatment sessions (Figure 2). Results showed a clear 


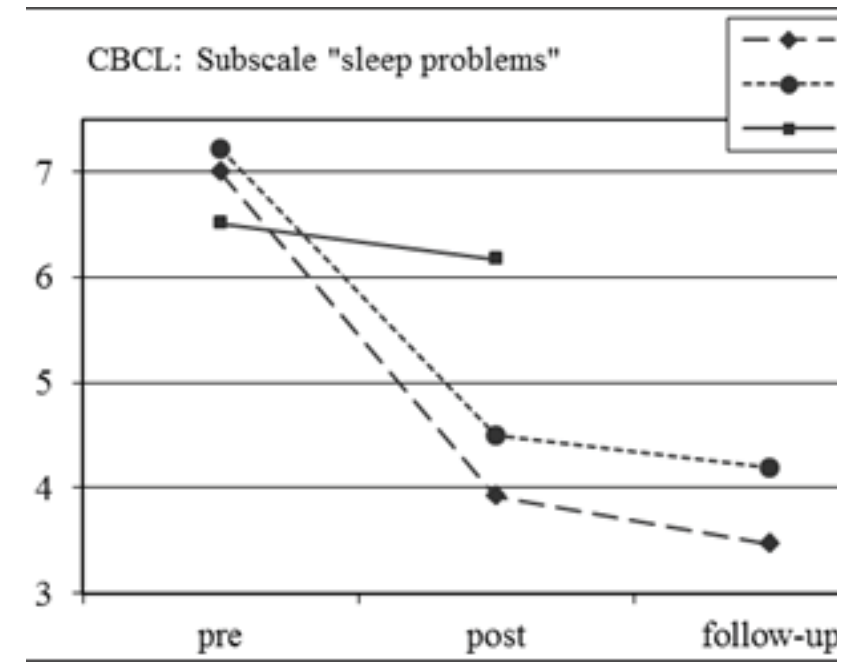

Figure 8: Subscale "sleep problems" of CBCL 1.5-5.

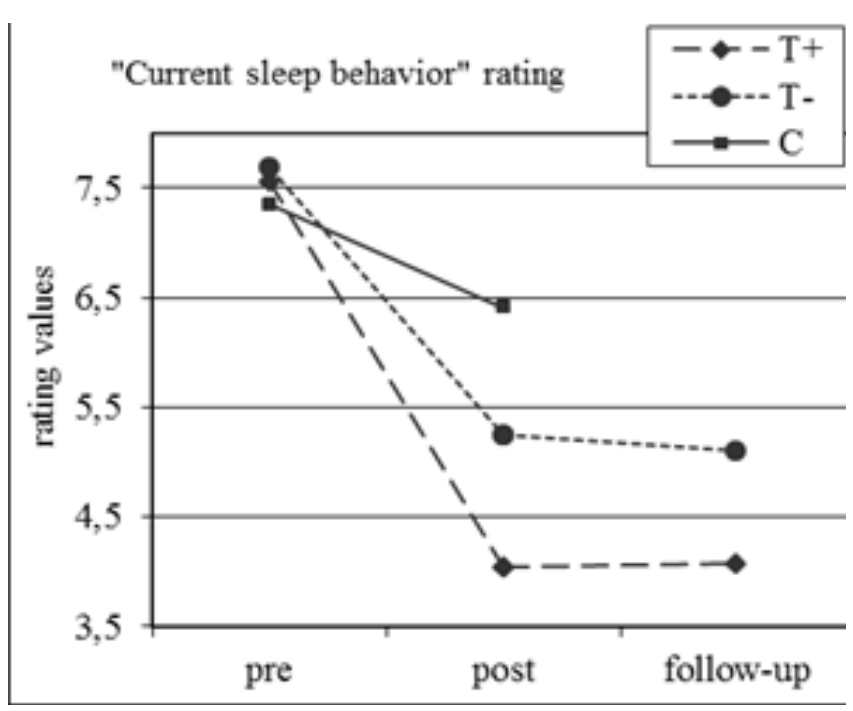

Figure 9: "Current sleep behavior" of MKO-AQ.

increase of these ratings for both conditions $\left(\mathrm{T}+/ \mathrm{CT}+\mathrm{Chi}^{2}=95.88\right.$, $\mathrm{p} \leq 0.001$; T-/CT-: $\left.\mathrm{Chi}^{2}=54.19, \mathrm{p} \leq 0.001\right)$. In detail, results showed improvement for $\mathrm{T}+/ \mathrm{CT}+$ between session one and two $(\mathrm{Z}=-4.19, \mathrm{p} \leq$ $0.001)$, between session five and $\operatorname{six}(Z=-3.39, p \leq 0.001)$, and a trend for comparison of session four and five $(\mathrm{Z}=-2.42, \mathrm{p}=0.016)$. Interestingly, for T-/CT- differences were just found for comparison between session one and two $(\mathrm{Z}=-4.19, \mathrm{p} \leq 0.000)$.

\section{Parental involvement}

Based on previous results, we expected a reduction in soothing behaviour of the parents in both treatment conditions (without advantage for $\mathrm{T}+$ ) without a change in the control condition. To detail parental behaviour in sleep onset and night waking situations, the following relative frequencies (range 0-1) from the sleep diaries were analysed: parental presence, physical contact, rocking the child and carrying the child to fall asleep for sleep onset or night waking situations. All mean values for parental involvement are presented in Table 9, the corresponding statistics in Table 10.
Parental presence: Results for pre-post comparison clearly showed that parents reduced their presence at sleep onset and night waking in both treatment conditions, while there was no change (at night) or even an increase (sleep onset) of their presence in C. These results became apparent in significant interaction terms for sleep onset and night waking situations. For both situations, $\mathrm{T}+$ showed no advantage compared to T-. Follow-up evaluation indicated stability of these effects.

Physical contact: Results of physical contact differed little between sleep onset and night waking situations. While there was a significant interaction effect at sleep onset situation (reduction in $\mathrm{T}+$ and $\mathrm{T}-$, no change in $\mathrm{C}$ ), there was just a time effect for night waking situation (reduction in all three groups). For sleep onset, no advantage for T+ compared to T- was found. Follow-up comparisons indicated stability of these effects after three months.

Rocking the child to sleep: In summary, parents in all conditions rarely reported rocking the child to sleep for sleep onset or night waking situations for all measurement points. Nevertheless, results indicated significant reductions of rocking the child between pre- and postmeasurement for $\mathrm{T}+$ and $\mathrm{T}$ - for sleep onset and night waking. Followup comparisons indicated stability of these effects after three months.

Carrying the child to sleep: In summary, parents rarely reported carrying the child to sleep for sleep onset or night waking situations for all measurement points. However, overall there was a trend for reduction of carrying the child for pre-post comparisons for sleep onset and night waking situations.

Pre-vs. follow-up comparisons: To clarify, not only stability of effects (post vs. follow-up) but existence of positive treatment outcomes between pre- and follow-up measurement additional analyses of variance were performed for $\mathrm{T}+$ and $\mathrm{T}$-. Confirmation of the former results was found for parental presence, physical contact and rocking the child to sleep for evening and night waking situations. Thereby, pre- vs. follow-up comparisons showed significant changes over time (significant main effect time) but independent of group affirmation (missing interaction term).

\section{Discussion}

The previous pilot-study [60] already demonstrated the acceptance and the potential affectivity of the Mini-KiSS Online program with regard to children's bedtime behaviour and parental strategies to soothe the child. The current study was performed to evaluate MiniKiSS Online in a randomized controlled trial. Three conditions were performed: 1) Written information only (T-); 2) Written information plus additional telephone support $(\mathrm{T}+)$; 3) Waiting-list control condition (C).

Data of the Treatment Evaluation Questionnaire indicated that the Internet-based intervention Mini-KiSS Online was highly accepted by parents. Not only were the parents glad to have participated and stated that they would recommend the training to other families, they were also attracted and motivated by the online training and they felt able to transfer the general information to their personal situation. These results are comparable with the observations of Griffiths and Christensen [57] in their review of Internet interventions for mental disorders indicating consistently positive evaluations by users of Internet interventions. Furthermore, these results are similar to high acceptance in other Internet interventions regarding sleep disturbances in young children [58].

Data of child sleep showed clear advantages for both treatment 
Citation: Schlarb AA, Brandhorst I, Peters E, Hautzinger M (2018) Telephone Support in an Internet-Based Treatment for Sleep Problems in Early Childhood. J Psychiatry 21: 435. doi:10.4172/2378-5756.1000435

Page 10 of 14

\begin{tabular}{|c|c|c|c|c|c|c|c|c|}
\hline \multirow[b]{2}{*}{ Variables } & \multicolumn{3}{|c|}{ pre } & \multicolumn{3}{|c|}{ post } & \multicolumn{2}{|c|}{ follow-up } \\
\hline & $\begin{array}{c}\text { T+ } \\
M(\text { (SD) }\end{array}$ & $\begin{array}{c}\text { T- } \\
M(S D)\end{array}$ & $\begin{array}{c}\text { C } \\
M(S D)\end{array}$ & $\begin{array}{c}\text { T+ } \\
M(\text { (SD) }\end{array}$ & $\begin{array}{c}\text { T- } \\
M(S D)\end{array}$ & $\begin{array}{c}\text { C } \\
M(S D)\end{array}$ & $\begin{array}{c}\stackrel{\mathbf{T +}}{\mathrm{M}}(\mathrm{SD})\end{array}$ & $\begin{array}{c}\text { T- } \\
M(S D)\end{array}$ \\
\hline Parental presence evening* & $\begin{array}{c}0.49 \\
(0.48)\end{array}$ & $\begin{array}{c}0.61 \\
(0.46)\end{array}$ & $\begin{array}{c}0.46 \\
(0.46)\end{array}$ & $\begin{array}{c}0.19 \\
(0.36)\end{array}$ & $\begin{array}{c}0.36 \\
(0.46)\end{array}$ & $\begin{array}{c}0.58 \\
(0.46)\end{array}$ & $\begin{array}{c}0.20 \\
(0.38)\end{array}$ & $\begin{array}{c}0.45 \\
(0.48)\end{array}$ \\
\hline Parental presence at night* & $\begin{array}{c}0.40 \\
(0.43)\end{array}$ & $\begin{array}{c}0.51 \\
(0.45)\end{array}$ & $\begin{array}{c}0.42 \\
(0.45)\end{array}$ & $\begin{array}{c}0.19 \\
(0.32)\end{array}$ & $\begin{array}{c}0.31 \\
(0.40)\end{array}$ & $\begin{array}{c}0.46 \\
(0.44)\end{array}$ & $\begin{array}{c}0.16 \\
(0.32)\end{array}$ & $\begin{array}{c}0.31 \\
(0.42)\end{array}$ \\
\hline Physical contact evening* & $\begin{array}{c}0.45 \\
(0.47)\end{array}$ & $\begin{array}{c}0.64 \\
(0.43)\end{array}$ & $\begin{array}{c}0.55 \\
(0.45)\end{array}$ & $\begin{array}{c}0.24 \\
(0.39)\end{array}$ & $\begin{array}{c}0.35 \\
(0.45)\end{array}$ & $\begin{array}{c}0.48 \\
(0.47)\end{array}$ & $\begin{array}{c}0.27 \\
(0.44)\end{array}$ & $\begin{array}{c}0.32 \\
(0.43)\end{array}$ \\
\hline Physical contact at night* & $\begin{array}{c}0.42 \\
(0.44)\end{array}$ & $\begin{array}{c}0.59 \\
(0.41)\end{array}$ & $\begin{array}{c}0.53 \\
(0.44)\end{array}$ & $\begin{array}{c}0.24 \\
(0.38)\end{array}$ & $\begin{array}{c}0.32 \\
(0.41)\end{array}$ & $\begin{array}{c}0.41 \\
(0.43)\end{array}$ & $\begin{array}{c}0.27 \\
(0.40)\end{array}$ & $\begin{array}{c}0.28 \\
(0.41)\end{array}$ \\
\hline Rocking evening ${ }^{*}$ & $\begin{array}{c}0.13 \\
(0.30)\end{array}$ & $\begin{array}{c}0.13 \\
(0.31)\end{array}$ & $\begin{array}{c}0.11 \\
(0.30)\end{array}$ & $\begin{array}{c}0.04 \\
(0.18)\end{array}$ & $\begin{array}{c}0.04 \\
(0.19)\end{array}$ & $\begin{array}{c}0.09 \\
(0.25)\end{array}$ & $\begin{array}{c}0.04 \\
(0.18)\end{array}$ & $\begin{array}{c}0.02 \\
(0.13)\end{array}$ \\
\hline Rocking at night* & $\begin{array}{c}0.06 \\
(0.18)\end{array}$ & $\begin{array}{c}0.11 \\
(0.26)\end{array}$ & $\begin{array}{c}0.04 \\
(0.13)\end{array}$ & $\begin{array}{c}0.02 \\
(0.12)\end{array}$ & $\begin{array}{c}0.03 \\
(0.15)\end{array}$ & $\begin{array}{c}0.03 \\
(0.14)\end{array}$ & $\begin{array}{c}0.02 \\
(0.12)\end{array}$ & $\begin{array}{c}0.03 \\
(0.16)\end{array}$ \\
\hline Carrying evening* & $\begin{array}{c}0.04 \\
(0.18)\end{array}$ & $\begin{array}{c}0.08 \\
(0.24)\end{array}$ & $\begin{array}{c}0.07 \\
(0.22)\end{array}$ & $\begin{array}{c}0.01 \\
(0.09)\end{array}$ & $\begin{array}{c}0.05 \\
(0.19)\end{array}$ & $\begin{array}{c}0.04 \\
(0.17)\end{array}$ & $\begin{array}{c}0.00 \\
(0.00)\end{array}$ & $\begin{array}{c}0.03 \\
(0.15)\end{array}$ \\
\hline Carrying at night* & $\begin{array}{c}0.05 \\
(0.17)\end{array}$ & $\begin{array}{c}0.05 \\
(0.15)\end{array}$ & $\begin{array}{c}0.04 \\
(0.15)\end{array}$ & $\begin{array}{c}0.02 \\
(0.11)\end{array}$ & $\begin{array}{c}0.01 \\
(0.05)\end{array}$ & $\begin{array}{c}0.01 \\
(0.06)\end{array}$ & $\begin{array}{c}0.00 \\
(0.00)\end{array}$ & $\begin{array}{c}0.02 \\
(0.11)\end{array}$ \\
\hline
\end{tabular}

Note: Data of post-measurement and follow-up include values from last-observation carried-forward. M: Mean; SD: Standard Deviation; T+: Treatment with personal assistance; T-: Treatment without personal assistance; C: Control condition; *: Values represent mean of yes (1) or no (0) answers to the corresponding questions of parental involvement in the evening or at night waking in sleep diary

Table 9: Mean and standard deviations for parental involvement.

\begin{tabular}{|c|c|c|c|c|c|c|c|c|c|c|c|}
\hline \multirow{2}{*}{$\begin{array}{c}\text { Parental involvement } \\
\text { (number of relative } \\
\text { frequencies) }\end{array}$} & \multirow{2}{*}{ Results } & \multicolumn{2}{|c|}{$\begin{array}{l}\text { Interaction effects: } \\
\text { time }{ }^{*} \text { group }\end{array}$} & \multicolumn{2}{|c|}{$\begin{array}{l}\text { Main effects: } \\
\text { time / group }\end{array}$} & \multicolumn{3}{|c|}{$\begin{array}{l}\text { Time comparisons*: } \\
\text { pre vs. post / post vs. follow-up }\end{array}$} & \multicolumn{3}{|c|}{$\begin{array}{l}\text { group comparison of pre-post or } \\
\text { post-follow-up differences }{ }^{\star *} \text { : }\end{array}$} \\
\hline & & $\mathrm{p}$-/F-value & $\begin{array}{l}\text { partial } \\
\text { eta }^{2}\end{array}$ & $p$-value & partial eta ${ }^{2}$ & $\mathrm{~T}-$ & $\mathrm{C}$ & $\mathrm{C}$ & $\begin{array}{c}\text { DT+ vs. } \\
\text { DT- }\end{array}$ & $\begin{array}{l}\text { DT+ vs. } \\
\text { DC }\end{array}$ & DT- vs. DC \\
\hline \multirow{2}{*}{$\begin{array}{l}\text { Parental presence } \\
\text { sleep onset }\end{array}$} & $\begin{array}{l}\text { pre vs. } \\
\text { post }\end{array}$ & $\begin{array}{c}F(2: 188)=13.72 \\
\mathbf{p} \leq 0.001\end{array}$ & 0.127 & $\begin{array}{l}\text { time: } \mathbf{p} \leq \mathbf{0 . 0 0 1} \\
\text { group: } \mathbf{p}=\mathbf{0 . 0 1 2}\end{array}$ & $\begin{array}{l}0.070 \\
0.046\end{array}$ & $\begin{array}{l}t=4.16 \\
p \leq 0.001\end{array}$ & $\begin{array}{c}t=3.66 \\
p \leq 0.001\end{array}$ & $\begin{array}{l}t=-2.52 \\
p=0.014\end{array}$ & $\begin{array}{l}t=-0.70 \\
p=0.484\end{array}$ & $\begin{aligned} t & =-4.86 \\
p & \leq 0.001\end{aligned}$ & $\begin{array}{l}t=-4.44 \\
p \leq 0.001\end{array}$ \\
\hline & $\begin{array}{l}\text { post vs. } \\
\text { follow-up }\end{array}$ & $\begin{array}{c}F(1: 126)=0.92 \\
p=0.339\end{array}$ & 0.007 & $\begin{array}{l}\text { time: } p=0.103 \\
\text { group: } p \leq \\
\mathbf{0 . 0 0 1}\end{array}$ & $\begin{array}{l}0.021 \\
0.080\end{array}$ & & & & $\begin{array}{r}t=-0.96 \\
p=0.339\end{array}$ & & \\
\hline \multirow{2}{*}{$\begin{array}{l}\text { Parental presence } \\
\text { night waking }\end{array}$} & $\begin{array}{l}\text { pre vs. } \\
\text { post }\end{array}$ & $\begin{array}{c}F(2: 176)=5.36 \\
p=0.006\end{array}$ & 0.057 & $\begin{array}{l}\text { time: } p=0.004 \\
\text { group: } p=0.051\end{array}$ & $\begin{array}{l}0.047 \\
0.033\end{array}$ & $\begin{array}{c}t=3.02 \\
p=0.004\end{array}$ & $\begin{array}{c}t=3.16 \\
p=0.003\end{array}$ & $\begin{array}{c}t=-0.91 \\
p=0.365\end{array}$ & $\begin{array}{l}t=-0.33 \\
p=0.742\end{array}$ & $\begin{array}{l}t=-2.84 \\
p=0.005\end{array}$ & $\begin{array}{l}t=-2.74 \\
p=0.007\end{array}$ \\
\hline & $\begin{array}{l}\text { post vs. } \\
\text { follow-up }\end{array}$ & $\begin{array}{c}F(1: 122)=0.18 \\
p=0.673\end{array}$ & 0.001 & $\begin{array}{l}\text { time: } p=0.716 \\
\text { group: } \mathbf{p}=\mathbf{0 . 0 1 5}\end{array}$ & $\begin{array}{l}0.001 \\
0.048\end{array}$ & & & & $\begin{array}{c}t=0.42 \\
p=0.673\end{array}$ & & \\
\hline \multirow{2}{*}{$\begin{array}{c}\text { Physical contact sleep } \\
\text { onset }\end{array}$} & $\begin{array}{c}\text { pre vs. } \\
\text { post }\end{array}$ & $\begin{array}{c}F(2: 188)=3.61 \\
p=0.029\end{array}$ & 0.037 & $\begin{array}{l}\text { time: } \mathbf{p} \leq \mathbf{0 . 0 0 1} \\
\text { group: } \mathbf{p}=\mathbf{0 . 0 2 2}\end{array}$ & $\begin{array}{l}0.151 \\
0.040\end{array}$ & $\begin{aligned} t & =3.86 \\
p & \leq 0.001\end{aligned}$ & $\begin{aligned} t & =4.30 \\
p & \leq \mathbf{0 . 0 0 1}\end{aligned}$ & $\begin{array}{c}t=1.44 \\
p=0.156\end{array}$ & $\begin{array}{c}t=0.91 \\
p=0.364\end{array}$ & $\begin{array}{l}t=-1.87 \\
p=0.064\end{array}$ & $\begin{array}{l}t=-2.58 \\
p=0.011\end{array}$ \\
\hline & $\begin{array}{l}\text { post vs. } \\
\text { follow-up }\end{array}$ & $\begin{array}{c}(1: 126)=1.43 \\
p=0.234\end{array}$ & 0.011 & $\begin{array}{l}\text { time: } p=0.910 \\
\text { group: } p=0.220\end{array}$ & $\begin{array}{l}0.000 \\
0.012\end{array}$ & & & & & & \\
\hline \multirow{2}{*}{$\begin{array}{l}\text { Physical contact night } \\
\text { waking }\end{array}$} & $\begin{array}{l}\text { pre vs. } \\
\text { post }\end{array}$ & $\begin{array}{c}F(2: 176)=1.48 \\
p=0.231\end{array}$ & 0.017 & $\begin{array}{l}\text { time: } \mathbf{p} \leq \mathbf{0 . 0 0 1} \\
\text { group: } p=0.052\end{array}$ & $\begin{array}{l}0.174 \\
0.033\end{array}$ & $\begin{aligned} t & =3.42 \\
p & \leq 0.001\end{aligned}$ & $\begin{aligned} t & =4.49 \\
p & \leq \mathbf{0 . 0 0 1}\end{aligned}$ & $\begin{array}{c}t=2.50 \\
p=0.015\end{array}$ & & & \\
\hline & $\begin{array}{l}\text { post vs. } \\
\text { follow-up }\end{array}$ & $\begin{array}{c}F(1: 122)=1: 70 \\
p=0.195\end{array}$ & 0.014 & $\begin{array}{c}\text { time: } p=0.965 \\
\text { group: } p=0.519\end{array}$ & $\begin{array}{l}0.000 \\
0.003\end{array}$ & & & & & & \\
\hline \multirow[t]{2}{*}{ Rocking sleep onset } & $\begin{array}{c}\text { pre vs. } \\
\text { post }\end{array}$ & $\begin{array}{c}F(2: 188)=1.73 \\
p=0.179\end{array}$ & 0.018 & $\begin{array}{l}\text { time: } \mathbf{p} \leq \mathbf{0 . 0 0 1} \\
\text { group: } p=0.814\end{array}$ & $\begin{array}{l}0.074 \\
0.002\end{array}$ & $\begin{array}{c}t=2.99 \\
p=0.004\end{array}$ & $\begin{array}{c}t=2.71 \\
p=0.009\end{array}$ & $\begin{array}{c}t=0.84 \\
p=0.406\end{array}$ & & & \\
\hline & $\begin{array}{l}\text { post vs. } \\
\text { follow-up }\end{array}$ & $\begin{array}{c}F(1: 126)=0.34 \\
p=0.561\end{array}$ & 0.003 & $\begin{array}{l}\text { time: } p=0.487 \\
\text { group: } p=0.655\end{array}$ & $\begin{array}{l}0.004 \\
0.002\end{array}$ & & & & & & \\
\hline \multirow[t]{2}{*}{ Rocking night waking } & $\begin{array}{c}\text { pre vs. } \\
\text { post }\end{array}$ & $\begin{array}{c}F(2: 176)=1.95 \\
p=0.146\end{array}$ & 0.022 & $\begin{array}{l}\text { time: } \mathbf{p} \leq \mathbf{0 . 0 0 1} \\
\text { group: } \mathbf{p}=0.317\end{array}$ & $\begin{array}{l}0.070 \\
0.013\end{array}$ & $\begin{array}{c}t=2.46 \\
p=0.017\end{array}$ & $\begin{array}{c}t=2.55 \\
p=0.014\end{array}$ & $\begin{array}{c}t=0.93 \\
p=0.354\end{array}$ & & & \\
\hline & $\begin{array}{l}\text { post vs. } \\
\text { follow-up }\end{array}$ & $\begin{array}{c}F(1: 122)=0.01 \\
p=0.917\end{array}$ & 0.000 & $\begin{array}{l}\text { time: } p=0.917 \\
\text { group: } p=0.574\end{array}$ & $\begin{array}{l}0.000 \\
0.003\end{array}$ & & & & & & \\
\hline \multirow{2}{*}{ Carrying sleep onset } & $\begin{array}{l}\text { pre vs. } \\
\text { post }\end{array}$ & $\begin{array}{c}F(2: 188)=0.31 \\
p=0.733\end{array}$ & 0.003 & $\begin{array}{l}\text { time: } \mathbf{p}=\mathbf{0 . 0 3 8} \\
\text { group: } p=0.371\end{array}$ & $\begin{array}{l}0.023 \\
0.011\end{array}$ & $\begin{array}{c}t=1.34 \\
p=0.184\end{array}$ & $\begin{array}{c}t=1.51 \\
p=0.137\end{array}$ & $\begin{array}{c}t=0.86 \\
p=0.395\end{array}$ & & & \\
\hline & $\begin{array}{l}\text { post vs. } \\
\text { follow-up }\end{array}$ & $\begin{array}{c}F(1: 126)=0.18 \\
p=0.673\end{array}$ & 0.001 & $\begin{array}{c}\text { time: } p=0.110 \\
\text { group: } p=0.126\end{array}$ & $\begin{array}{c}0.020 \\
0.0019\end{array}$ & & & & & & \\
\hline \multirow{2}{*}{ Carrying night waking } & $\begin{array}{l}\text { pre vs. } \\
\text { post }\end{array}$ & $\begin{array}{c}(2: 176)=0.06 \\
p=0.941\end{array}$ & 0.001 & $\begin{array}{c}\text { time: } \mathbf{p}=\mathbf{0 . 0 2 2} \\
\text { group: } p=0.842\end{array}$ & $\begin{array}{l}0.029 \\
0.002\end{array}$ & $\begin{array}{c}t=1.16 \\
p=0.251\end{array}$ & $\begin{array}{c}t=1.58 \\
p=0.120\end{array}$ & $\begin{array}{c}t=1.32 \\
p=0.190\end{array}$ & & & \\
\hline & $\begin{array}{l}\text { post vs. } \\
\text { follow-up }\end{array}$ & $\begin{array}{c}F(1: 122)=1.71 \\
p=0.194\end{array}$ & 0.014 & $\begin{array}{l}\text { time: } p=0.445 \\
\text { group: } p=0.550\end{array}$ & $\begin{array}{l}0.005 \\
0.003\end{array}$ & & & & & & \\
\hline
\end{tabular}

Notes: Analysis of pre and post data include all three groups (T+: T-: C) while comparison of follow-up data is based on post- and follow-up-values of T+ and T- only. Data of post-measurement and follow-up include values from last-observation carried-forward

T+: Treatment with personal assistance; T-: Treatment without personal assistance; C: Control condition; DT+: Difference in T+ between pre- and post-measurement; DT-: Difference in T- between pre- and post-measurement; DC: Difference in C between pre- and post-measurement; bold: significant value (after Bonferroni-Holm correction for all t-tests); *: T-tests were only performed in case of significant interaction effect or significant main effect of time; ${ }^{* *}$ : T-tests were only performed in case of (almost) significant interaction effect 
conditions compared to the waiting-list control condition. Most importantly, children in both treatment conditions showed significant reduction in sleep onset latency and duration of night waking, while there was no or less change in the control condition. Both changes caused improvements in sleep efficiency. In addition, all three conditions showed a reduced frequency of night waking, with a slight advantage for both treatment conditions.

These observations are in line with data of Mindell et al. [58] with their Internet-based intervention for mild sleep problems of infants and toddler (6-36 months of age). In their intervention they gave 1) a normative comparison of the child's sleep to other children, 2) a rating of whether their child is a good or disrupted sleeper, and 3) customized written advice on how parents can help their child to improve sleep. One of the two intervention groups of Mindell et al. [58] was additionally instructed to follow a nightly bedtime routine (bath, lotion/massage, quiet activities). The control condition just answered pre- and post-measurement. Mindell et al. [58] found improvements in sleep onset latency, duration and number of night waking's, as well as an increase in total night time sleep in both treatment conditions (Internet intervention vs. Internet intervention + standardized bedtime routine) compared to the control condition [58].

Furthermore, our results from a sleep diary were confirmed by more subjective measurements. Highly significant treatment effects were found for both intervention conditions compared to no (CBCL 1.5-5) or less (Anamnestic Questionnaire) change in the control condition. Additionally, the current study demonstrated a clear reduction in parental soothing-behaviour in both treatment conditions while there was no or less change or even an increase in controls. For example, parents of the treatment conditions showed less parental presence, less physical contact and less rocking the child to sleep after treatment. Overall, these results are in line with data of our pilot study [60] and similar to observations of Reid, Walter and O'Leary [67] showing that mothers of young children (16-48 months old) demonstrate high compliance when instructed to reduce their involvement at sleep onset and night waking. The authors further concluded that compliance was higher when instructing graduate extinction method compared to standard extinction [67].

To investigate stability of all these effects, both treatment conditions repeated the measurements at a 3-month follow-up. Altogether, all variables showed stability or further improvements (e.g. frequency of night waking and CBCL subscale "sleep problems") of the previously reported effects in pre- vs. follow-up and post vs. follow-up comparisons. Overall, these results are comparable with several other intervention studies improving sleep disturbances in young children [31-34,45,68] and other Internet-based intervention for sleep disorders in adults [50-54].

Mini-KiSS Online treatment increased 24 hrs.' sleep duration in both treatment conditions while there was no change in controls. Comparing the total sleep duration of the Mini-KiSS Online clinical subgroup ( $M=704$ minutes) with a healthy subgroup of Iglowstein et al. [69] ( $M=798$ minutes, children aged 0.5 to 4 years) it becomes obvious that our clinical sample shows less overall sleep before and after treatment. However, this could also be cohort effects (1974-1978 vs. 2012-2013) or measurement effects (telephone interview vs. sleep diary). Moreover, the mean overall sleep duration in our sample is comparable to other sleep disturbed subgroups (714 minutes) [70].

Because previous researchled to contradictory results we investigated the effect of additional telephone support. In summary, our results confirmed that personal advice is not necessary to further improve sleep problems of young children or to further reduce parental involvement. These results are in line with data of Seymour et al. [39] which showed no advantage of face-to-face counselling plus daily telephone support compared to written information only in their 4 weeks intervention program for parents of sleep disturbed young children ( 9 months to 5 years of age). Nevertheless, in ours study parents of $\mathrm{T}+$ perceived higher improvement according to the anamnestic questionnaire. Furthermore, parents of $\mathrm{T}+$ more often perceived improvement due to Mini-KiSS Online, they were more glad to have participated, they more often state they would recommend the Online training to other families, and they felt more encouraged by the Online training compared to families of TMost of these parents in $\mathrm{T}+(92 \%)$ specified that personal contact was very important for the success of their training while $69 \%$ of parents in $\mathrm{T}$ - quoted that personal assistance would have been important for them. These results are in line with data of Eckerberg [38] who compared personal assistance (therapist face-to-face consultation plus additional telephone support) to written information only in their 2 weeks treatment for parents of young children (mean age 9.8 months) with sleep disturbances. The author found no advantage of personal advice concerning sleep related outcome but apparent higher parental satisfaction with given support in the personal advice group. However, these results are opposed to data of Mimeault and Morin [46] demonstrating that adults with insomnia show a behaviour benefit from telephone support, while the groups (with/without telephone support) did not differ in their treatment evaluation (treatments credibility, acceptability, appropriateness, effectiveness and degree of satisfaction). Furthermore, parents in our study showed similar developments in both treatment conditions at the 3-month follow-up. Contrary, in the study of Mimeault and Morin [46] the initial advantage of adults getting personal advice disappeared at their 3-month follow-up because they were not able to stabilize their improvements. On the one hand, these results underline the sustainability of the Mini-KiSS Online treatment independent of personal assistance. On the other hand, there might be differences in the effects of personal advice when addressing the index patient or a caregiver.

\section{Challenges in internet-based interventions}

One of the most important challenges in self-help approaches or online treatments are dropout rates [36,48,71]. Different Internetintervention studies for several health problems and age groups yielded dropout rates between $2 \%$ and $83 \%$ in different reviews [36,71,72]. Our mean dropout rate was quite low (10.1\%) compared to dropout rates of Internet-based treatment of insomnia for adults (24\%) [54] or parents of young children (2,9\%) [58]. The last result might be affected by payment to each participating family ( $\$ 90$ to $\$ 175$ ) [58]. In the current study dropout rates after pre-measurement in $\mathrm{T}+(6.9 \%)$ were lower than in T- (17.2\%). This result is in line with experiences of Mimeault and Morin [46] showing higher dropout in adults treated with a pure bibliotherapeutic approach for insomnia compared to those with additional telephone support. Furthermore, a meta-analysis demonstrates that higher response rates in Web studies are associated with higher number of (personalized) contacts [73]. As Melville et al [71] concluded in their review article, clients receiving more immediate therapist contact may be more likely to feel involved and connected to their therapist, and that might decrease the risk for terminating treatment.

One further challenge in Internet-based interventions is the difficulty to examine if participants really use the provided information and materials. Limitations in treatment compliance (e.g. not completing 
exercises, not visiting the web-pages, too short durations signed-on) are well known difficulties in this area of research $[51,72,74]$. In the current study $24 \%$ of participants did not return one or more of the weekly requested exercises. Furthermore, the majority of mothers reported to have preferred executing the training alone, even though parents had been recommended to perform the sessions together. However, treatment non-compliance does not need to be interpreted as treatment failure. For example, Winzelberg et al. [74] did not find an association between treatment compliance and outcome. It might be that participants take what they need. In line with this, some parents in our studies reported discontinuing with Mini-KiSS Online because of success after the first few treatment sessions [75,76]. However, similar to factors influencing dropout, a multicomponent model affecting adherence seems to be more appropriate [71,72]. For example, Christensen, Griffiths and Farrer [72] identified several predictors for adherence in their review of Internet interventions for depression and anxiety in adults: lower baseline symptomatology, age of the patient, poorer knowledge of psychological treatment, experience with a computer and living with a partner.

Another challenge is the required duration of the intervention. Significant improvements in the current study were observed between session one and session two while further improvements between sessions four, five and six were only apparent in the treatment condition with personal assistance. These results are similar to data of our pilot study showing significant improvements between session two and three [60] and other similar investigations showing treatment effects after two to three weeks $[38,58]$. Based on these results, one could assume that one to three weeks might be sufficient for treating sleep problems in young children. But on the other hand, $33 \%$ of parents in our sample asked for an extension of their treatment plan, $17 \%$ felt to be under negative pressure, and $21 \%$ did not cope well with the time comprises of the Online training. These experiences are in the direction of to those of Reid et al. [67], showing that many parents interrupt their treatment schedule due to different reasons (child illness, parent absence, family not sleeping at home). Additionally, as Howard et al. demonstrated, the attitude in therapy research is quite common that more sessions or trials are necessary to produce significant or clinical changes [77]. Furthermore, it is not clear if the additional treatment sessions are necessary to stabilize the initial improvements. Further research should investigate if parents generally benefit from longer treatment durations in internet based treatments, if higher numbers of sessions are necessary to stabilize the primary effects, or if "less is more".

\section{Limitations of this work}

Some limitations have to be mentioned. First, demographic data indicate that our sample was not representative for the general German population. Parents were higher educated (59\% to $64 \%$ had university degree). However, these observations are comparable with other online interventions for sleep disturbed young children showing a high level of parental education (64-69\% college degree or higher) [58]. Furthermore, these observations are in accordance with studies showing higher education and occupation as relevant predictors for health related Internet use [49]. Second, comparison of initial group differences showed that children in T- might have more sleep maintenance problems than children of $\mathrm{T}+$ or $\mathrm{C}$. So one could argue that families were more affected by the sleep maintenance problem of their child and therefore were more motivated to execute and carry on with the online training. However, if this would be the fact, smaller dropout rates in this subgroup would have been expected. Furthermore, groups differed in their education of fathers. However, we do not expect a relevant influence of this to our data. Third, this study did not include objective measures like actigraphy or videosomnography. Multi-method, multi-reporter data including such objective measures can reduce bias that may result from parental reports of outcome data [31]. Moreover, as described in the previous section, treatment compliance was not fully given. Further studies should not only focus on outcome measures in principal, but also analyse treatment effects of participants showing treatment compliance. Furthermore, as already mentioned, this study was faced with moderate dropout rates. However, this fact was compensated for by the use of the conservative intent-totreat method. In addition, the results were limited to essentially small to medium effect sizes [78]. It is not known if the improvements lead to clinical significance. Future studies including long-term outcomes (>3 month) should investigate if the multi-component approach of Mini-KiSS Online is really necessary, or whether there are certain basic intervention elements (like graduate extinction) that are fundamental or sufficient for treatment efficacy.

\section{Conclusion}

Mini-KiSS Online is an effective and highly accepted internet-based intervention to reduce sleep problems in young children. Personal telephone assistance seems to count for higher satisfaction and lower dropouts but not for further improvement of the sleep behaviour of the child.

\section{References}

1. Thunström M (1999) Severe sleep problems among infants in a normal population in Sweden: prevalence, severity and correlates. Acta Paediatr 88: 1356-1363.

2. Archbold KH, Pituch KJ, Panabi P, Chervin RD (2002) Symptoms of sleep disturbances among children at two general pediatric clinics. J Pediatr 140 97-102.

3. Mindell JA, Sadeh A, Kwon R, Goh DYT (2013) Cross-cultural differences in the sleep of preschool children. Sleep Med 14: 1283-1289.

4. Jenni OG, Fuhrer HZ, Iglowstein I, Molinari L, Largo RH (2005) A longitudina study of bed sharing and sleep problems among Swiss children in the first 10 years of life. Pediatrics 115: 233-240.

5. Davis KF, Parker KP, Montgomery GL (2004) Sleep in infants and young children: Part Two: Common sleep problems. J Pediatr Health Care 18: 130137

6. Martin J, Hiscock H, Hardy P, Davey B, Wake M (2007) Adverse associations of infant and child sleep problems and parent health: an Australian population study. Pediatrics 119: 947-955.

7. Wake M, Morton-Allen E, Poulakis Z, Hiscock H, Gallagher S, et al. (2006) Prevalence, stability, and outcomes of cry-fuss and sleep problems in the firs 2 years of life: Prospective community-based study. Pediatrics 117: 836-842.

8. Cloud D, Meyer R, Ohrt B, Riegel K (1994) Frequency and persistence of pre-school and postnatal problems: Results of a prospective study on a representative sample in Bavaria. Practice of Child Psychology and Child Psychiatry 43: 331-339.

9. Zuckerman B, Stevenson J, Bailey V (1987) Sleep problems in early childhood Continuities, predictive factors, and behavioral correlates. Pediatrics 80: 664671

10. Byars KC, Yolton K, Rausch J, Lanphear B, Beebe DW (2012) Prevalence patterns, and persistence of sleep problems in the first 3 years of life. Pediatrics 129: $276-284$.

11. Thunström M (2002) Severe sleep problems in infancy associated with subsequent development of attention-deficit/hyperactivity disorder at 5.5 years of age. Acta Paediatr 91: 584-592.

12. Owens JA (2005) The ADHD and sleep conundrum: A review. J Dev Behav Pediatr 26: 312-322.

13. Schwebel DC, Brezausek CM (2008) Nocturnal awakenings and pediatric 
injury risk. J Pediatr Psychol 33: 323-332.

14. Valent $F$, Brusaferro S, Barbone $F(2001)$ A case-crossover study of sleep and childhood injury. Pediatrics 107: 23.

15. Lam P, Hiscock H, Wake M (2003) Outcomes of infant sleep problems: A longitudinal study of sleep, behavior and maternal well-being. Pediatrics 111: 203-207.

16. Bell JF, Zimmerman FJ (2010) Shortened nighttime sleep duration in early life and subsequent childhood obesity. Arch Pediat Adol Med 164: 840-845.

17. Magee L, Hale L (2012) Longitudinal associations between sleep duration and subsequent weight gain: A systematic review. Sleep Med Rev 16: 231-241.

18. Ednick M, Cohen AP, McPhail GL, Beebe D, Simakajornboon N, et al. (2009) A review of the effects of sleep during the first year of life on cognitive psychomotor, and temperament development. Sleep 32: 1449.

19. Johnson CM (1991) Infant and toddler sleep: A telephone survey of parents in one community. J Dev Behav Pediatr 12: 108-114.

20. Morrell J, Steele H (2003) The role of attachment security, temperament maternal perception, and care-giving behavior in persistent infant sleeping problems. Inf Mental HIth J 24: 447-468.

21. Sadeh A, Anders TF (1993) Infant sleep problems: Origins, assessment interventions. Inf Mental HIth J 14: 17-34.

22. Anders TF, Halpern LF, Hua J (1992) Sleeping through the night: A developmental perspective. Pediatrics 90: 554-560.

23. Goodlin-Jones BL, Burnham MM, Gaylor EE, Anders TF (2001) Night waking, sleep-wake organization, and self-soothing in the first year of life. J Dev Behav Pediatr 22: 226.

24. Sadeh A (2005) Cognitive-behavioral treatment for childhood sleep disorder Clin Psychol Rev 25: 612-628.

25. Mindell JA, Sadeh A, Kohyama J, How TH (2010) Parental behaviors and sleep outcomes in infants and toddlers: a cross-cultural comparison. Sleep Med 11: 393-399.

26. Petit D, Touchette E, Tremblay RE, Boivin M, Montplaisir J (2007) Dyssomnias and parasomnias in early childhood. Pediatrics 119: e1016-1025.

27. Sadeh A, Mindell JA, Lüdtke K, Wiegand B (2009) Sleep and sleep ecology in the first 3 years: A web-based study. J Sleep Res 18: 60-73

28. Burnham MM, Goodlin-Jones BL, Gaylor EE, Anders TF (2002) Nighttime sleepwake patterns and self-soothing from birth to one year of age: A longitudinal intervention study. J Child Psychol Psychiatry 431: 713-725.

29. Kerr SM, Jowett SA, Smith LN (1996) Preventing sleep problems in infants: A randomized controlled trial. J Adv Nurs 24: 938-942.

30. Wolfson A, Lacks P, Futterman A (1992) Effects of parent training on infan sleeping patterns, parents' stress, and perceived parental competence. J Consult Clin Psych 60: 41.

31. Meltzer LJ, Mindell JA (2014) Systematic review and meta-analysis of behavioral interventions for pediatric insomnia. J Pediatr Psychol 39: 932-948.

32. Mindell JA (1999) Bedtime problems and night wakings: Treatment of behaviora insomnia of children. J Pediatr Psychol 24: 465-481.

33. Mindell JA, Kuhn B, Lewin DS, Meltzer LJ, Sadeh (2006). Behavioral treatment of bedtime problems and night wakings in infants and young children. Sleep 29: $1263-1276$

34. https://academic.oup.com/sleep

35. Owens LJ, France KG, Wiggs L (1999) Behavioural and cognitive-behavioura interventions for sleep disorders in infants and children: A review. Sleep Med Rev 3: 281-302.

36. Tikotzky L, Sadeh A (2010) The role of cognitive-behavioral therapy in behavioral childhood insomnia. Sleep Med 11: 686-691.

37. Cuijpers P, van Straten A, Andersson G (2008) Internet-administered cognitive behaviour therapy for health problems: a systematic review. J Behav Med 31: 169-177.

38. Thorndike FP (2009) Commentary: Interest in internet interventions-an infant sleep program as illustration. J Pediatr Psychol 34: 470-473.

39. Eckerberg B (2002) Treatment of sleep problems in families with small children:
Is written information enough? Acta Paediatr 91: 952-959.

40. Seymour F, Brock P, During M, Poole G (1989) Reducing sleep disruptions in young children: evaluation of therapist-guided and written information approaches. J Child Psychol Psychiatry 30: 913-918.

41. Weymouth J, Hudson A, King N (1987) The management of children's nighttime behaviour problems: Evaluation of an advice booklet. Behavioural Psychotherapy 15: 123-133.

42. Gould RA, Clum GA (1993) A meta-analysis of self-help treatment approaches Clin Psychol Rev 13: 169-186.

43. Marrs RW (1995) A meta-analysis of bibliotherapy studies. Am J Commun Psychol 23: 843-870

44. Andersson G, Lundström P, Ström L (2003) Internet-based treatment of headache: Does telephone contact add anything? Headache 43: 353-361.

45. Hiscock H, Wake M (2002) Randomised controlled trial of behavioural infant sleep intervention to improve infant sleep and maternal mood. Brit Med J 324 1062.

46. James-Roberts ST, Sleep J, Morris S, Owen C, Gillham P (2001) Use of a behavioural programme in the first 3 months to prevent infant crying and sleeping problems. J Paediatr Child 37: 289-297.

47. Mimeault V, Morin CM (1999) Self-help treatment for insomnia: bibliotherapy with and without professional guidance. J Consult Clin Psych 67: 511-519.

48. Spek V, Cuijpers P, Nyklicek I, Riper H, Keyzer J, et al. (2007) Internet-based cognitive behaviour therapy for symptoms of depression and anxiety: a metaanalysis. Psychol Med 37: 319-328.

49. Glasgow RE, Rosen GM (1987) Behavioral bibliotherapy: A review of self-help behavior therapy manuals. Psychol Bull 85: 1-23.

50. Lausen B, Potapov S, Prokosch HU (2007) Gesundheitsbezogene Internetnutzung in Deutschland 2007. GMS Medizinische Informatik, Biometrie und Epidemiologie 4: 1-12.

51. Ritterband LM, Bailey ET, Thorndike FP, Lord HR, Farrell LV, et al. (2012) Initia evaluation of an Internet intervention to improve the sleep of cancer survivors with insomnia. Psychooncology 21: 659-705.

52. Ritterband LM, Thorndike FP, Gonder-Federick LA, Magee JC, Bailey ET, et al. (2009) Efficacy of an Internet-Based Behavioral Intervention for Adults With Insomnia. Arch Gen Psychiatry 66: 692-698.

53. Thorndike FP, Ritterband LM, Gonder-Frederick LA, Lord HR, Ingersoll KS, et al. (2013) A randomized controlled trial of an internet intervention for adults with insomnia: Effects on comorbid psychological and fatigue symptoms. J Clin Psychol 69: 1078-1093.

54. Thorndike FP, Saylor DK, Bailey ET, Gonder-Frederick L, Morin CM, et al. (2008) Development and perceived utility and impact of an internet intervention for insomnia. J Appl Psychol 4: 32-42.

55. Ström L, Pettersson R, Andersson G (2004) Internet-based treatment for insomnia: A controlled evaluation. J Consult Clin Psych 72: 113-120.

56. Barak A, Hen L, Boniel-Nissim M, Shapira N (2008) A comprehensive review and an meta-analysis of the effectiveness of internet-based psychotherapeutic interventions. J Technol Hum Serv 26: 109-160.

57. Eichenberg C, Ott R (2012) Klinisch-psychologische Intervention im Internet. Psychotherapeut 57: 58-69.

58. Griffiths KM, Christensen $\mathrm{H}$ (2006) Review of randomised controlled trials of Internet interventions for mental disorders and related conditions. Clinical Psychologist 10: 16-29.

59. Mindell JA, Du Mond CE, Sadeh A, Telofski LS, Kulkarni N, et al. (2011) Efficacy of an internet-based intervention for infant and toddler sleep disturbances. Sleep 34: 451

60. Mindell JA, Du Mond CE, Sadeh A, Telofski LS, Kulkarni N, et al. (2011) Long term efficacy of an internet-based intervention for infant and toddler sleep disturbances: One year follow-up. J Clin Sleep Med 7: 507-511.

61. Schlarb AA, Brandhorst I (2012) Mini-KiSS online: An internet-based intervention program for parents of young children with sleep problemsinfluence on parental behavior and children's sleep. Nat Sci Sleep 4: 41.

62. Statistisches Bundesamt (2012) Statistisches Jahrbuch. 
Citation: Schlarb AA, Brandhorst I, Peters E, Hautzinger M (2018) Telephone Support in an Internet-Based Treatment for Sleep Problems in Early Childhood. J Psychiatry 21: 435. doi:10.4172/2378-5756.1000435

63. Achenbach TM, Rescorla LA (2000) Manual for the ASEBA preschool forms \& profiles: An integrated system of multi-informant assessment. University of Vermont, Burlington.

64. Gaylor EE, Burnham MM, Goodlin-Jones BL, Anders TF (2005) A longitudinal follow-up study of young children's sleep patterns using a developmental classification system. Behav Sleep Med 3: 44-61.

65. Mazumdar S, Liu KS, Houck PR, Reynolds CF (1999) Intent-to-treat analysis for longitudinal clinical trials coping with the challenge of missing values. J Psychiatr Res 33: 87-95.

66. Stevens J (1999) Intermediate statistics. A modern approach.

67. Brown JD (2008) Effect size and eta squared. JALT Testing \& Evaluation SIG Newsletter 12: 38-43.

68. Reid MJ, Walter AL, O'Leary SG (1999) Treatment of young children's bedtime refusal and night time waking's: A comparison of "standard" and graduated ignoring procedures. J Abnorm Child Psych 27: 5-16.

69. Kuhn BR, Elliott AJ (2003) Treatment efficacy in behavioural paediatric sleep medicine. J Psychosom Res 54: 587-597.

70. Iglowstein I, Jenni OG, Molinari L, Largo RH (2003) Sleep duration from infancy to adolescence: Reference values and generational trends. Pediatrics 111: 302-307.

71. Mindell JA, Telofski LS, Wiegand B, Kurtz ES (2009) A nightly bedtime routine: Impact on sleep in young children and maternal mood. Sleep 32: 599.

72. Melville KM, Casey LM, Kavanagh DJ (2010) Dropout from internet-based treatment for psychological disorders. Brit J Clin Psychol 49: 455-471.
73. Christensen $\mathrm{H}$, Griffiths KM, Farrer L (2009) Adherence in internet interventions for anxiety and depression: systematic review. J Med Internet Res 11: e13.

74. Cook C, Heath F, Thompson RL (2000) A meta-analysis of response rates in web- or Internet-based surveys. Educ Psych Measurem 60: 821-836.

75. Winzelberg AJ, Eppstein D, Eldredge KL (2000) Effectiveness of an internetbased program for reducing risk factors for eating disorders. J Consult Clin Psych 68: 346.

76. Lange A, van de Ven JP, Schrieken B, Emmelkamp PM (2001) Interapy, treatment of posttraumatic stress through the Internet: A controlled trial. J Behav Ther Exp Psy 32: 73-90.

77. Warmerdam L, van Straten A, Twisk J, Riper H, Cuijpers P (2008) Internetbased treatment for adults with depressive symptoms: randomized controlled trial. J Med Internet Res 10: e44

78. Kopta SM (2003) The dose-effect relationship in psychotherapy: A defining achievement for Dr. Keeneth Howard. J Clin Psychol 59: 727-733. 